\title{
Rhythm generation by the pre-Bötzinger Complex in medullary slice and island preparations: Effects of adenosine $A_{1}$ receptor activation

\author{
Richard J VanDam ${ }^{\dagger}$, Edward J Shields ${ }^{\dagger}$ and Jonathan D Kelty*
}

Address: Department of Biology, Central Michigan University, Mount Pleasant, MI 48858, USA

Email: Richard J VanDam - vanda1rj@cmich.edu; Edward J Shields - shiel1ej@cmich.edu; Jonathan D Kelty* - kelty1jd@cmich.edu

* Corresponding author †Equal contributors

Published: | October 2008

BMC Neuroscience 2008, 9:95 doi:10.1 186//47|-2202-9-95

This article is available from: http://www.biomedcentral.com/I47I-2202/9/95

(c) 2008 VanDam et al; licensee BioMed Central Ltd.

This is an Open Access article distributed under the terms of the Creative Commons Attribution License (http://creativecommons.org/licenses/by/2.0), which permits unrestricted use, distribution, and reproduction in any medium, provided the original work is properly cited.
Received: I 3 July 2007

Accepted: I October 2008

\begin{abstract}
Background: The pre-Bötzinger complex (preBötC) is a central pattern generator within the ventrolateral medulla oblongata's ventral respiratory group that is important for the generation of respiratory rhythm. Activation of adenosine $A_{1}$ receptors $\left(A_{1} R\right)$ depresses preBötC rhythmogenesis. Although it remains unclear whether $A_{1} R$ activation is important for organisms in a normal metabolic state, $A_{1} R$ activation is important to the response of the preBötC to metabolic stress, such as hypoxia. This study examined mechanisms linking $A_{1} R$ activation to depression of preBötC rhythmogenesis in medullary slice and island preparations from neonatal mice.
\end{abstract}

Results: Converting medullary slices to islands by cutting away much of the medullary tissue adjacent to the preBötC decreased the amplitude of action potential bursts generated by a population of neurons within the preBötC (recorded with an extracellular electrode, and integrated using a hardware integrator), without noticeably affecting burst frequency. The $A_{1} R$ agonist $\mathrm{N}^{6}-$ Cyclopentyladenosine (NCPA) reduced population burst frequency in slices by ca. $33 \%$ and in islands by ca. $30 \%$. As in normal (drug-free) artificial cerebrospinal fluid (aCSF), NCPA decreased burst frequency in slices when $G A B A_{A}$ ergic or $G A B A_{A}$ ergic and glycinergic transmission were blocked, and in islands when $G A B A_{A}$ ergic transmission was antagonized. Converting slices to island preparations decreased synaptic input to inspiratory neurons. NCPA further decreased the frequency of synaptic inputs to neurons in island preparations and lowered the input resistance of inspiratory neurons, even when chemical communication between neurons and other cells was impeded.

Conclusion: Together these data support the suggestion that depression of preBötC activity by $A_{1} R$ activation involves both decreased neuronal excitability and diminished inter-neuronal communication.

\section{Background}

The pre-Bötzinger complex (preBötC) within the medulla oblongata's ventral respiratory group (VRG) contains a network of neurons important for the generation of venti- latory (inspiratory) rhythmogenesis [1,2]. Even within a $1 / 2$-mm thick transverse slice of medulla the preBötC produces rhythmic bursts of neuronal activity that resemble various patterns of inspiration such as eupneic inspira- 
tion, gasps, and sighs [2-7]. Modulation of preBötC rhythmogenesis represents a central focus of research into this region's function. Within transverse medullary slice preparations from neonatal mice, preBötC rhythmogenesis and pattern formation are thought to result from the activity of a heterogeneous population of interneurons, which includes a variety of intrinsically-bursting pacemaker neurons as well as a variety of follower neurons [1,7-10]. Accordingly, modulation of preBötC rhythmogenesis likely involves regulation of multiple aspects of network function, including the modulation of membrane properties and of synaptic interactions [6,11-13].

Adenosine is an important modulator of neuronal network function throughout the CNS [14-17]. For instance, antagonizing adenosine $A_{1}$ receptors $\left(A_{1} R\right)$ inhibits hypoxic depression of synaptic transmission between hippocampal neurons [15]. Adenosine and $A_{1} R$ agonists tend to depress respiratory rhythmogenesis in a variety of neonatal mammals. This finding holds true at the level of the whole organism as well as for in vitro preparations containing the preBötC [18-23]. For instance, activation of $\mathrm{A}_{1} \mathrm{R}$ depresses inspiration-related network activity recorded from hypoglossal (XII) nerve rootlets of brainstem-spinal cord preparations obtained from embryonic and neonatal rats, as well as within medullary slice preparations from neonatal mice [22-24]. Depression of respiratory rhythmogenesis by $A_{1} R$ may be mediated by its effects on membrane properties, such as increasing conductance of leak $\mathrm{K}^{+}$channels in preBötC neurons [24]. Network-level depression by $\mathrm{A}_{1} \mathrm{R}$ may also involve reduced synaptic release. Activation of $\mathrm{A}_{1} \mathrm{R}$ pre-synaptically suppresses evoked glutamatergic EPSCs [16] and glycinergic IPSCS [25] in hypoglossal neurons by roughly 42 and $72 \%$, respectively.

Although its role or roles appear to evolve through ontogeny, fast inhibitory synaptic transmission is important in the functioning of central respiration-related networks in mammals ranging from neonatal through adult. In adult mammals inhibitory synaptic transmission appears to be necessary for respiratory rhythmogenesis. For instance, in adult cats antagonism of glycine receptors can block preBötC rhythmogenesis, and injection of the $\mathrm{GABA}_{\mathrm{A}}$ antagonist bicuculline into the preBötC slows respiratory rhythm and induces apneusis [26]. By contrast, the glycine receptor antagonist strychnine injected into the preBötC of adult rats is ineffective in altering phrenic nerve discharge [27]. Within in situ preparations from juvenile rats blocking glycinergic transmission can contribute to changing burst shape from incrementing to decrementing [28]. Antagonizing $\mathrm{GABA}_{\mathrm{A}}$-ergic and glycinergic transmission increases the frequency respiration-related bursts of neuronal activity generated by brainstem slices from neonatal mice [29-31] and brainstem spinal cord preparations
[29]. Moreover, blocking $\mathrm{GABA}_{\mathrm{A}}$ and glycine receptors increases the amplitude of integrated bursts generated by brainstem slices [30], increases the area of integrated bursts produced by brainstem spinal cord preparations and medullary slice preparations [29], increases the excitability in the medullary slice preparation [31], and allows medullary slice preparations to generate rhythmic bursts when bathed in $3 \mathrm{mM} \mathrm{K}^{+}$, rather than $8 \mathrm{mM} \mathrm{K}^{+}$[32]. Activation of $\mathrm{GABA}_{\mathrm{A}}$ receptors in brainstem spinal cord and slice preparations from embryonic (on or after embryonic day 19) and neonatal rats slows respiration-related bursting when the preparations are bathed in artificial cerebrospinal fluid (aCSF) containing $3 \mathrm{mM} \mathrm{K}^{+}$, but increases burst frequency when the preparation are bathed in aCSF with elevated extracellular $\mathrm{K}^{+}(9 \mathrm{mM})$ [33]. Thus, within in vitro preparations from neonatal mice and rats, inhibitory synaptic transmission affects the pattern of respirationrelated output, rather than being required for rhythmogenesis.

The purpose of this study was to examine factors that may contribute to, or interact with, $\mathrm{A}_{1} \mathrm{R}$-mediated depression of preBötC rhythmogenesis including effects of $A_{1} R$ activation on synaptic transmission and membrane properties. Since $\mathrm{GABA}_{A}$ ergic and glycinergic transmission affect the pattern of pre-BötC output, the effect of $A_{1} R$ activation on inputs via these transmitters was examined as proxy for the effects of $A_{1} R$ activation on fast chemical transmission in general. Although the pattern of respiration-related bursting in medullary slice preparations from neonatal mice is altered during $\mathrm{GABA}_{\mathrm{A}}$ and glycine receptor antagonism its persistence provides the opportunity to determine whether baseline $\mathrm{GABA}_{\mathrm{A}}$ ergic/Glycinergic transmission and the effects of $\mathrm{A}_{1} \mathrm{R}$ activation interact. That is, when $\mathrm{GABA}_{\mathrm{A}}$ ergic or $\mathrm{GAB}_{\mathrm{A}}$ Aergic and glycinergic transmission are left intact, is the network-level depression observed during $A_{1} R$ activation more extensive than when synaptic input is reduced or when $\mathrm{GABA}_{A}$ or $\mathrm{GABA}_{\mathrm{A}}$ and glycine receptors are extensively antagonized?

Whereas this study used $\mathrm{GABA}_{\mathrm{A}}$ ergic and glycinergic antagonists to extensively block these forms of fast chemical transmission, the effects of less severe reduction in intra- and/or inter-network synaptic transmission on the preBötC's population-level response to $A_{1} R$ activation were examined by comparing the actions of the $A_{1} R$ agonist $\mathrm{N}^{6}$-Cyclopentyladenosine (NCPA) in medullary slice preparations and preBötC island preparations. Reducing the medullary slice to an island preparation removes regions including the inferior olivary complex (IO), spinal trigeminal tract (SP5), nucleus tractus solitarius (NTS), medullary raphe, XII nucleus, facial nucleus, and contralateral preBötC [34]. As with the medullary slice preparation, portions of the VRG abutting the preBötC (along the rostro-caudal axis) remain in the island. Conversion to 
the island preparation severs the axons of many neurons projecting to the preBötC, and may reduce intra-network communication, with the net effect being a reduction in the amount of input received by preBötC neurons as show in the results section below [c.f. [34]]. Thus, many or most of the currents observed in preBötC neurons within the island preparation are likely evoked by transmitters released from preBötC neurons, or from other VRG neurons.

The data presented herein demonstrate that $A_{1} R$ activation depresses preBötC rhythmogenesis similarly in otherwise untreated slice preparations, when synaptic input is reduced by converting the slice to an island, and in slice preparations within which $\mathrm{GABA}_{A}$ ergic or $\mathrm{GABA}_{\mathrm{A}}$ ergic and glycinergic receptors were antagonized. This study further demonstrates that during its depression of preBötC rhythmogenesis $A_{1} R$ activation decreases synaptic input to preBötC neurons and alters resting membrane properties in a manner consistent with decreased neuronal excitability. Together these findings support the notion that although the synaptic currents/potentials evoked by baseline levels of GABA and glycine may integrate with the modulatory effects of $A_{1} R$ activation, their contribution is too small to be noticed at the level of population level recordings. Rather the effects of $A_{1} R$ activa- tion on membrane properties and/or synaptic release are sufficient to cause substantial depression of the preBötC.

\section{Results}

\section{Effects of $A_{l} R$ agonism/antagonism on preBötC population activity in slice preparations}

Pharmacological manipulation of $A_{1} R$ affected the generation of population bursts by the preBötC (Repeated Measures ANOVA $\mathrm{P}<0.001$; Table 1 ). The $\mathrm{A}_{1} \mathrm{R}$ agonist NCPA $(1 \mu \mathrm{M})$ decreased population burst frequency by $27.3 \%$ ( $P<0.001$; Fig. 1A, B. Subsequent addition of the $\mathrm{A}_{1} \mathrm{R}$ antagonist 1,3-Dipropyl-8-cyclopentylxanthine (DPCPX; $1 \mu \mathrm{M}, \mathrm{n}=12$ ) returned population bursting to essentially baseline frequency $(\mathrm{P}<0.001$ vs. NCPA; Fig. $1 \mathrm{~A}, \mathrm{~B})$. The amplitude of population bursts generated during NCPA treatment was statistically indistinguishable from that of bursts generated during baseline recording (Repeated Measures ANOVA, P > 0.1; Table 1).

\section{Effects of $A_{l} R$ manipulation on slice rhythmogenesis during $G A B A_{A}$ receptor antagonism}

A second set of experiments determined whether the postsynaptic effects of $\mathrm{GABA}_{A}$ ergic transmission integrate with (effectively sum with) the effects of $\mathrm{A}_{1} \mathrm{R}$ activation to increase the level of network-level depression of preBötC rhythmogenesis in the medullary slice preparation. Note:

Table I: Effects of $A_{1} R$ activation on population burst parameters

\begin{tabular}{|c|c|c|c|c|c|c|c|}
\hline & & & Slice & & & Island & \\
\hline Treatment Group & Stage of Experiment & $\mathrm{n}$ & $\begin{array}{l}\text { Frequency } \\
\text { (bursts } \text { sec }^{-1} \text { ) }\end{array}$ & Amplitude & $\mathrm{n}$ & $\begin{array}{l}\text { Frequency } \\
\text { (bursts } \cdot \sec ^{-1} \text { ) }\end{array}$ & Amplitude \\
\hline \multirow[t]{4}{*}{ aCSF control } & I. Baseline & 12 & $0.33 \pm 0.02$ & $2.01 \pm 0.24$ & 9 & $0.37 \pm 0.04$ & $1.39 \pm 0.25$ \\
\hline & 2. aCSF & & $0.33 \pm 0.03$ & $2.03 \pm 0.25$ & & $0.36 \pm 0.04$ & $1.50 \pm 0.31$ \\
\hline & 3. NCPA & & $0.24 \pm 0.03$ & $2.13 \pm 0.24$ & & $0.26 \pm 0.04 \mathrm{a}, \mathrm{b}$ & $1.57 \pm 0.40$ \\
\hline & 4. DPCPX & & $0.31 \pm 0.02$ & $1.81 \pm 0.22$ & & $0.37 \pm 0.03$ & $1.48 \pm 0.44$ \\
\hline \multirow[t]{4}{*}{ Bicuculline } & I. Baseline & II & $0.36 \pm 0.03$ & $1.65 \pm 0.23$ & 7 & $0.44 \pm 0.06$ & $1.13 \pm 0.19$ \\
\hline & 2. Bicuculline & & $0.33 \pm 0.02$ & $2.27 \pm 0.35^{\mathrm{a}}$ & & $0.43 \pm 0.05$ & $1.77 \pm 0.29 \mathrm{a}$ \\
\hline & 3. NCPA & & $0.22 \pm 0.03^{a, b}$ & $2.33 \pm 0.35^{\mathrm{a}}$ & & $0.41 \pm 0.05$ & $1.55 \pm 0.2 \mathrm{I}^{\mathrm{a}}$ \\
\hline & 4. DPCPX & & $0.31 \pm 0.03$ & $1.93 \pm 0.30$ & & $0.48 \pm 0.07$ & $1.81 \pm 0.37 \mathrm{a}$ \\
\hline \multirow{4}{*}{ Gabazine } & I. Baseline & 7 & $0.34 \pm 0.07$ & $3.10 \pm 1.14$ & 6 & $0.27 \pm 0.04$ & $0.89 \pm 0.10$ \\
\hline & 2. Gabazine & & $0.33 \pm 0.06$ & $3.48 \pm 1.24$ & & $0.29 \pm 0.03$ & $0.86 \pm 0.10$ \\
\hline & 3. NCPA & & $0.25 \pm 0.07^{a}, b$ & $2.56 \pm 0.89$ & & $0.18 \pm 0.05^{a, b}$ & $0.89 \pm 0.15$ \\
\hline & 4. DPCPX & & $0.32 \pm 0.06$ & $3.37 \pm 1.11$ & & $0.30 \pm 0.05$ & $0.76 \pm 0.09$ \\
\hline \multirow[t]{4}{*}{ Gabazine \& Strychnine } & I. Baseline & 8 & $0.33 \pm 0.05$ & $0.97 \pm 0.16$ & 6 & $0.40 \pm 0.06$ & $1.15 \pm 0.16$ \\
\hline & 2. Gabazine + Strychnine & & $0.30 \pm 0.04$ & $1.40 \pm 0.20$ & & $0.40 \pm 0.05$ & $1.46 \pm 0.23^{a}$ \\
\hline & 3. NCPA & & $0.24 \pm 0.03^{a}, \mathrm{~b}$ & $1.31 \pm 0.23$ & & $0.34 \pm 0.05$ & $1.51 \pm 0.26^{a}$ \\
\hline & 4. DPCPX & & $0.30 \pm 0.03$ & $1.10 \pm 0.17$ & & $0.38 \pm 0.04$ & $1.45 \pm 0.26^{a}$ \\
\hline
\end{tabular}

Slices were superfused with one of four solutions prior to treatment with NCPA (aCSF alone, aCSF with bicuculline, aCSF with gabazine, or aCSF with gabazine and strychnine).

'All values presented as mean \pm SEM.

${ }^{a}$ Different from baseline (pre-treatment) value at $\mathrm{P}<0.05$ (Tukey post-hoc tests)

bDifferent from control (aCSF only) at $\mathrm{P}<0.05$ (Tukey post-hoc tests) 
A

Baseline (pre-treatment)

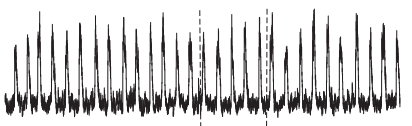

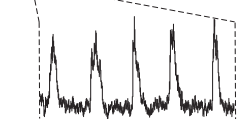

aCSF
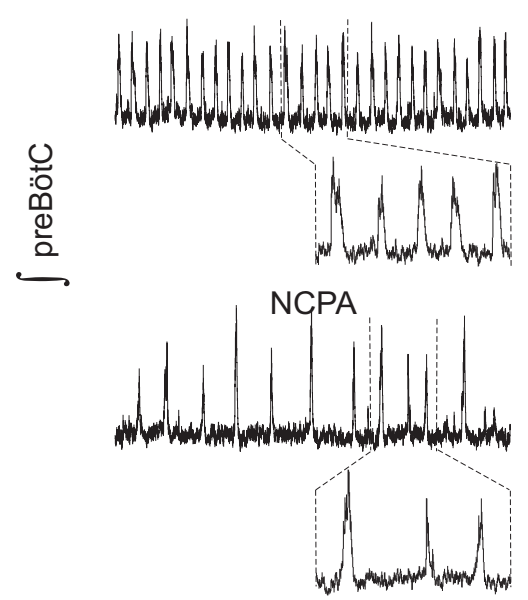

DPCPX

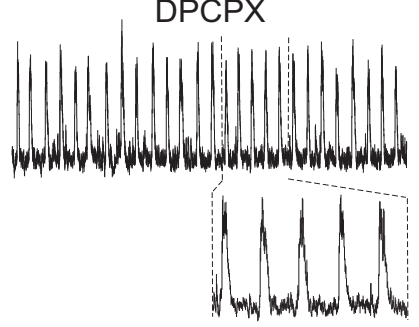

B. i.

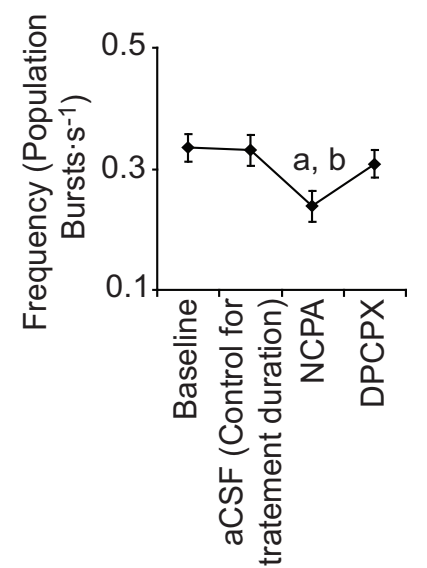

Baseline
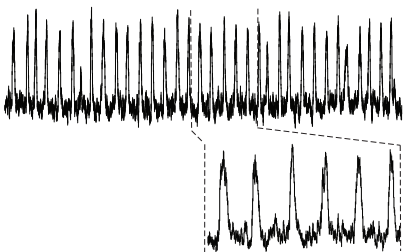

$\mathrm{GABA}_{\mathrm{A}}$ Antagonist (Gabazine)

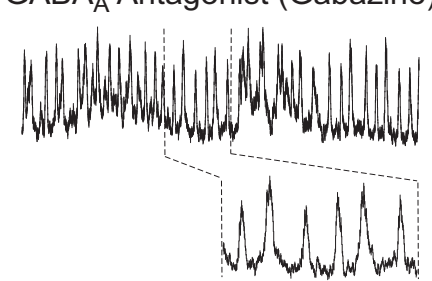

NCPA
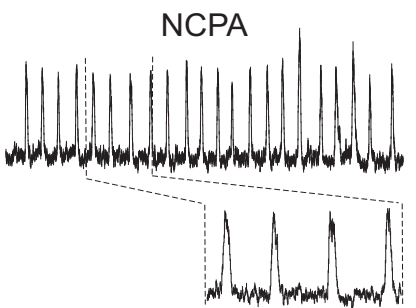

DPCPX

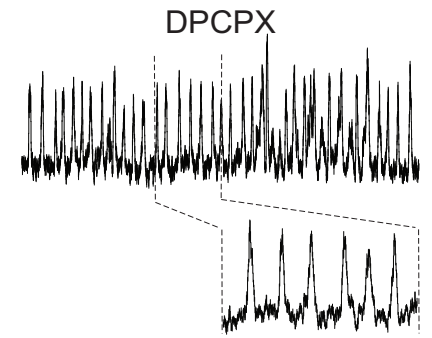

ii.

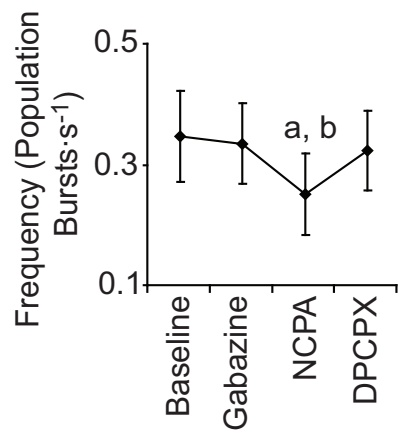

iii.
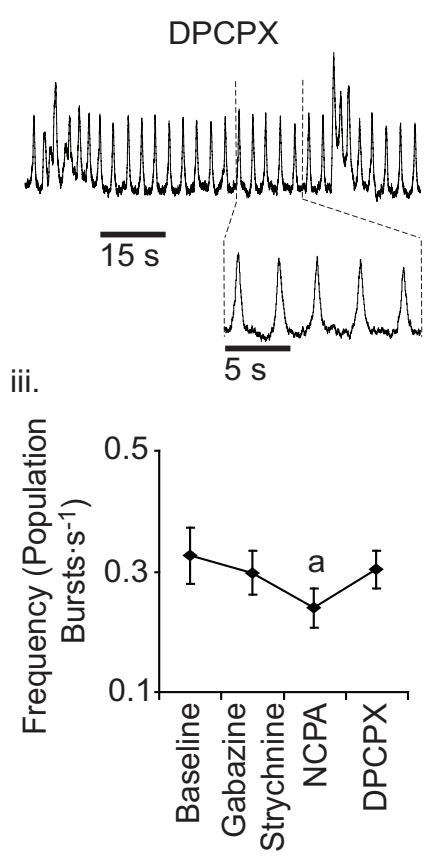

Figure I

Effects of $A_{1} R$ activation on preBötC rhythmogenesis in medullary slice preparations. A. Representative effects of bath-applied NCPA $(I \mu M)$ alone, NCPA in the presence of gabazine $(20 \mu \mathrm{M})$, or NCPA in combination with gabazine $(20 \mu M)$ and strychnine $(\mathrm{I} \mu \mathrm{M})$. B. Whether applied (i) alone, (ii) with gabazine, or (iii) with gabazine and strychnine, NCPA decreased burst frequency $(\mathbf{a}$, value different from baseline at $P<0.05$, Tukey post-hoc test; $\mathbf{b}$, value different from step 2 of treatment either continued aCSF, application of gabazine, or application of gabazine and strychnine - at $P<0.05$, Tukey post-hoc test). 
an alternative hypothesis could be that $A_{1} R$ activation substantially increases extracellular levels of GABA and/or glycine thereby depressing the activity of postsynaptic neurons and thus depressing network activity. However, given that $A_{1} R$ activation tends to depress synaptic transmission throughout the nervous system $[16,25]$, such an effect is unlikely. Due to potential non-specific effects of bicuculline on neuronal properties, a subset of experiments used gabazine $(20 \mu \mathrm{M})$, rather than bicuculline to antagonize $\mathrm{GABA}_{\mathrm{A}}$ receptors. NCPA decreased the overall frequency of population bursts in slices by 33\% during bicuculline treatment $(\mathrm{n}=11 ; \mathrm{P}<0.001$; Table 1$)$ and by $\sim 24.2 \%$ during gabazine treatment $(\mathrm{n}=7 ; \mathrm{P}<0.05$; Fig. $1 \mathrm{~A}, \mathrm{Bii})$. These changes in frequency were indistinguishable from the $\sim 27.3 \%$ decrease observed in slices treated with NCPA alone. As with slices treated with NCPA alone, DPCPX applied during treatment with NCPA and bicuculline returned population burst frequency to a level $(0.31$ $\pm 0.03 \mathrm{~Hz}$ ) statistically indistinguishable from baseline. Similarly, in slices treated with gabazine and NCPA, DPCPX increased population burst frequency to a level indistinguishable from treatment with gabazine alone (Table 1).

Population burst amplitude varied between treatments in slice preparations treated with the $\mathrm{GABA}_{\mathrm{A}}$ receptor antagonist bicuculline (Repeated measures ANOVA, $\mathrm{P}=0.002$ ), but not in slices treated with gabazine (Repeated Measures ANOVA, $\mathrm{P}=0.815$; Table 1). Bicuculline increased the amplitude of population-level bursting (Tukey Post-Hoc Test, $\mathrm{P}=0.009$; Table 1). Agonism/antagonism of $\mathrm{A}_{1} \mathrm{R}$ during antagonism of $\mathrm{GABA}_{\mathrm{A}}$ receptors with bicuculline or gabazine produced no statistically detectable change in mean burst amplitude (Table 1).

\section{Effects of $A_{1} R$ manipulation on slice rhythmogenesis during $\mathrm{GABA}_{A}$ and glycine receptor antagonism}

In all 8 slices examined, a cocktail of gabazine $(20 \mu \mathrm{M})$ and strychnine $(1 \mu \mathrm{M})$ induced seizure-like bursting at $1.36 \pm 0.22$ siezures $\cdot \mathrm{min}^{-1}$ (Fig. 2. During subsequent agonism of $\mathrm{A}_{1} \mathrm{R}$ with NCPA seizures occurred at $0.71 \pm$ 0.47 seizures $\cdot \mathrm{min}^{-1}\left(\mathrm{P}>0.05\right.$, Tukey Test). Blockade of $\mathrm{Cl}^{-}$ -mediated transmission did not discernibly affect the overall frequency of population bursting. Even with $\mathrm{GABA}_{\mathrm{A}}$ ergic and glycinergic transmission antagonized, NCPA decreased the frequency of population bursts relative to baseline (Fig. 1A, B; $\mathrm{P}=0.002$, Tukey Test). This change in frequency was indistinguishable from the $\sim 27.2 \%$ decrease observed in slices treated with NCPA alone. Although a repeated measures ANOVA indicated significant overall variation in amplitude between all treatments (in slices treated with gabazine and strychnine; $\mathrm{P}=0.044$ ), Tukey post-hoc tests demonstrated that none of the individual pairs of treatments were distinguishable from each other (Table 1).
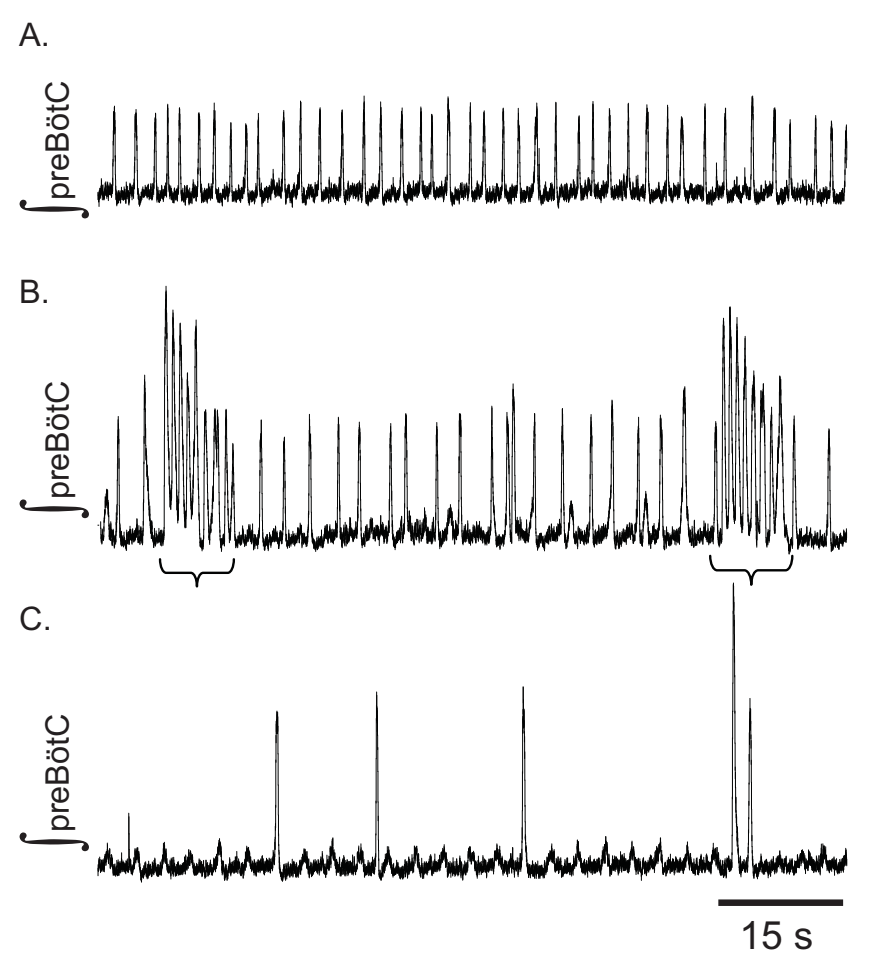

Figure 2

Block of chloride-mediated inhibition inducesseizurelike activity in medullary slice preparations. Three sequential sample recordings of integrated preBötC activity from a single medullary slice preparation. A. Activity recorded in recorded in drug free aCSF. B. Gabazine $(20 \mu \mathrm{M})$ and Strychnine (I $\mu \mathrm{M})$ induce seizure-like bursting (brackets) characterized by increased burst frequency and elevated baseline, while slightly decreasing the frequency of population bursts generated between seizure-like bursts. $C$. Antagonism of $A_{1} R$ with NCPA ( $\left.I \mu M\right)$ eliminated seizures for this slice and decreased population burst frequency.

\section{Effects of $A_{1} R$ agonism/antagonism on preBötC population activity in island preparations}

The slices from which island preparations were excised and the islands generated from them produced population bursts at similar frequencies (Fig. 3. However, population burst amplitude decreased with conversion from slice to island preparation ( $\mathrm{n}=9 ; \mathrm{P}<0.001 ;$ Fig. 3$)$. As with slice preparations, NCPA decreased the frequency of population bursts generated by islands, in this case from $0.37 \pm 0.04$ to $0.26 \pm 0.04 \mathrm{~Hz}(\mathrm{n}=9 ; \mathrm{P}<0.001$; Table 1$)$. This decrease ( $29.8 \%)$ was indistinguishable from the $27.3 \%$ decrease observed in slices treated with NCPA alone. Subsequent application of DPCPX, in the continued presence of NCPA, increased the frequency of population bursting to a level indistinguishable from baseline $(0.37 \pm 0.03$ Hz; Tukey Test, $\mathrm{P}<0.001$, vs. NCPA; Fig. 4 . Population burst amplitude remained similar between 


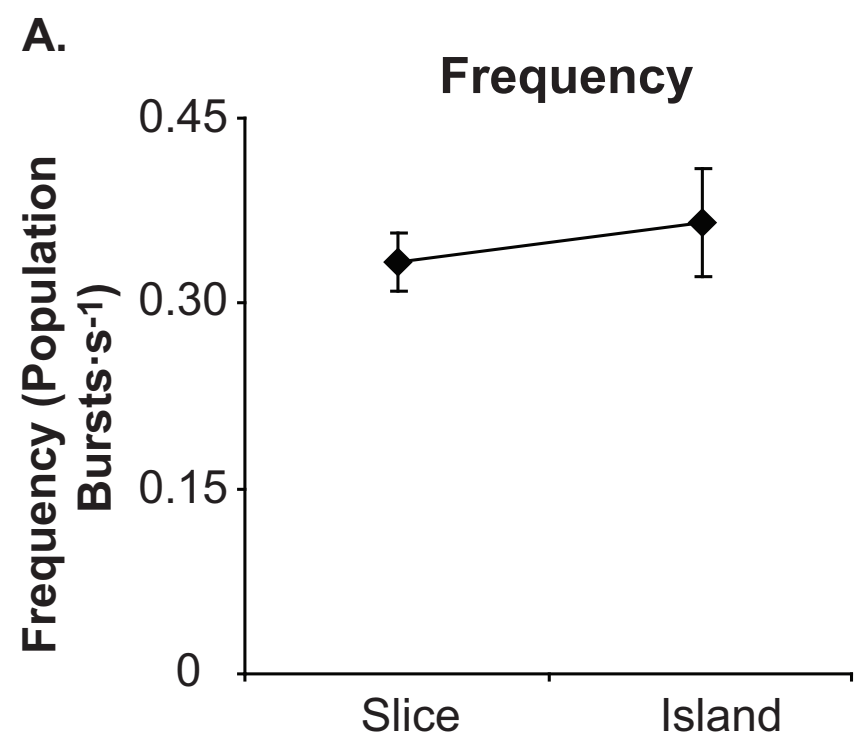

B.

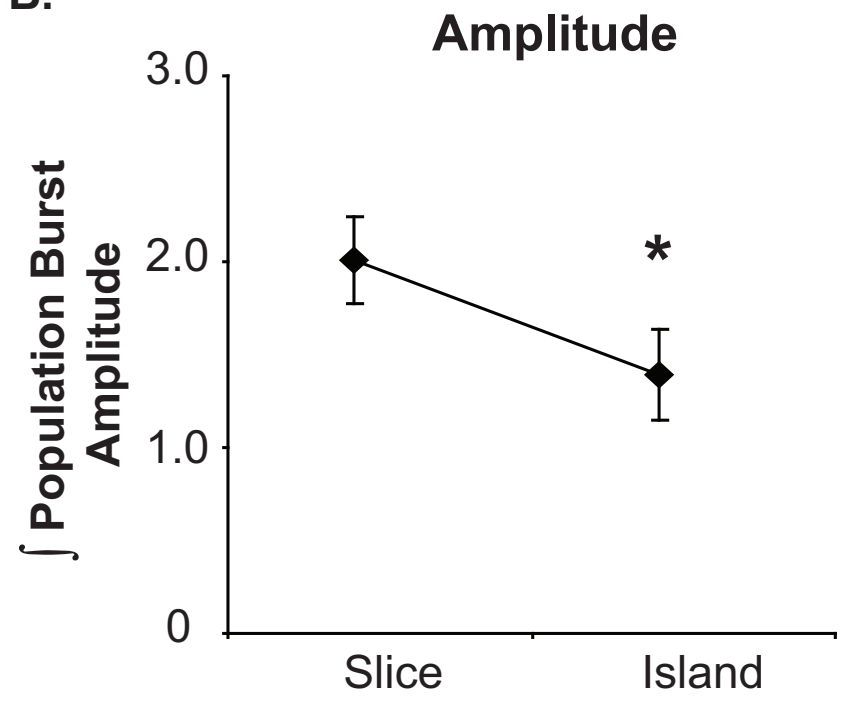

Figure 3

Effects of slice to island conversion onpopulation burst parameters. A. The frequency of population bursts generated by the preBötC was unchanged by cutting away regions of the slice preparation adjacent to the preBötC (see text), thereby converting the section to an island preparation (frequency $=0.33 \pm 0.02 \mathrm{~Hz}$ in slices vs. $0.37 \pm 0.04 \mathrm{~Hz}$ in islands; $n=13$ of each; paired t-test, $P=0.73$ ). $B$. By contrast, the amplitude of integrated population bursts decreased by $30.1 \%$ with conversion of the slice to the island preparation (*, $\mathrm{P}<0.05$, paired t-test). treatments in island preparations (Repeated measures ANOVA, $\mathrm{P}=0.547$; Table 1).

\section{Effects of $A_{1} R$ manipulation on island rhythmogenesis during $G A B A_{A}$ receptor antagonism}

The frequency of population bursts generated by island preparations remained near baseline levels following addition of bicuculline (Tukey Test, $\mathrm{n}=7, \mathrm{P}=0.981$; Table 1). By contrast to slices, NCPA applied to islands in the presence of bicuculline failed to change population burst frequency relative to baseline (Tukey test, $\mathrm{n}=7, \mathrm{P}=$ $0.493)$. As in slice preparations, bicuculline increased population burst amplitude in island preparations (Tukey test, $\mathrm{P}=0.027$; Table 1 ), which effectively remained unchanged during subsequent treatment with NCPA (Tukey test, $\mathrm{P}=0.695$; Table 1 ).

By contrast to its effects in the presence of bicuculline, NCPA applied in the presence of gabazine decreased the frequency of population bursting in island preparations (Tukey test, $\mathrm{n}=6, \mathrm{P}<0.001$; Fig. 4). Moreover, $\mathrm{A}_{1} \mathrm{R}$ activation reduced burst frequency to a greater extent in gabazine-treated islands than in gabazine-treated slices causing a $37.9 \%$ decrease in island burst frequency compared to a $24.2 \%$ decrease in gabazine treated slices (t-test, $\mathrm{P}=0.0002)$. As with bicuculline, gabazine caused no detectable change in population burst frequency in island preparations (Fig. 4A, Bii). Unlike bicuculline, gabazine caused no discernible change in the amplitude of population bursts in island preparations. However, in the presence of gabazine burst amplitude remained relatively constant during treatment with NCPA (Table 1).

\section{Effects of $A_{1} R$ manipulation on island rhythmogenesis during $G_{A B A_{A}}$ and glycine receptor antagonism}

Population burst frequency was seemingly unaffected by combined $\mathrm{GABA}_{\mathrm{A}}$ and glycine receptor antagonism, with islands generating population bursts at $0.40 \pm 0.09 \mathrm{~Hz}$ under baseline conditions and at $0.40 \pm 0.08 \mathrm{~Hz}$ in the presence of gabazine and strychnine ( $n=6$; Fig. 4A, Biii). By contrast to medullary slices, the combination of gabazine and strychnine evoked no seizures in island preparations. In the presence of gabazine and strychnine, NCPA failed to cause a statistically detectable change in population burst frequency or amplitude (Repeated measure ANOVA, $\mathrm{n}=6, \mathrm{P}=0.16$; Table 1 ).

\section{Effects of $A_{l} R$ activation on synaptic inputs}

With the solutions used during this study all synaptic inputs appeared to evoke inward currents in neurons voltage-clamped at $-60 \mathrm{mV}$ (Fig. 5A. Thus, to discriminate between inhibitory inputs and excitatory inputs inspiratory neurons were voltage clamped at $-35 \mathrm{mV}$, at which $\mathrm{Cl}^{-}$ -mediated currents appeared as outward events and excitatory currents appeared as inward events (Fig. 5B). Dur- 
A.
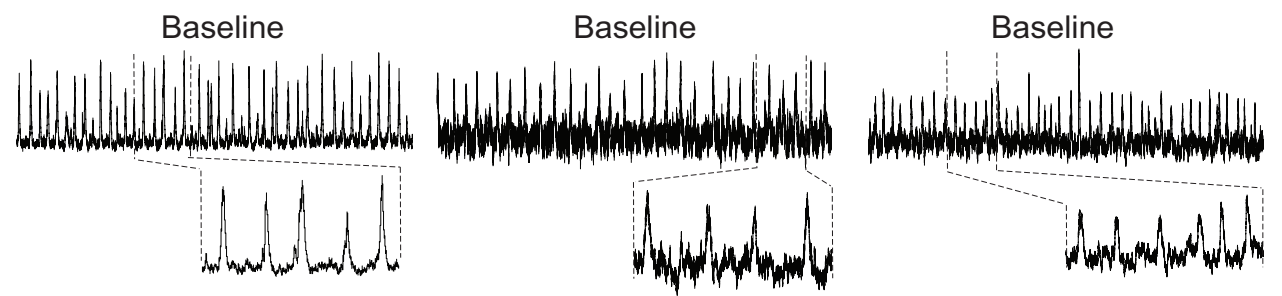

aCSF

$\mathrm{GABA}_{\mathrm{A}}$ Antagonist (Gabazine)
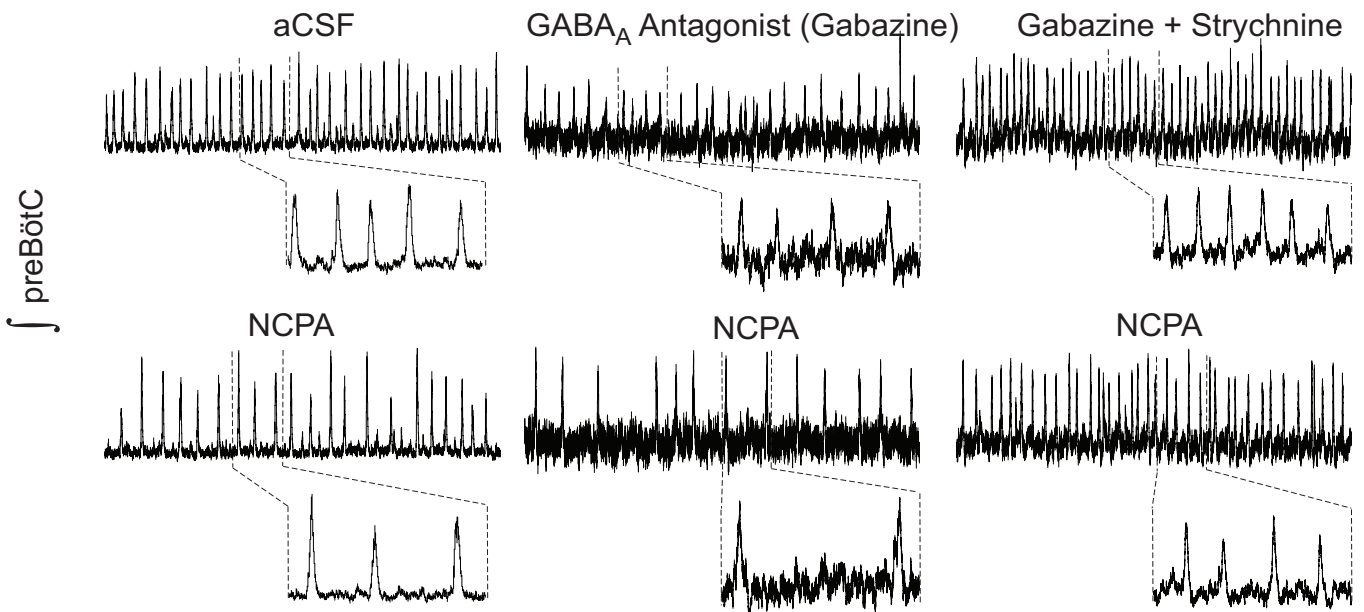

NCPA

NCPA
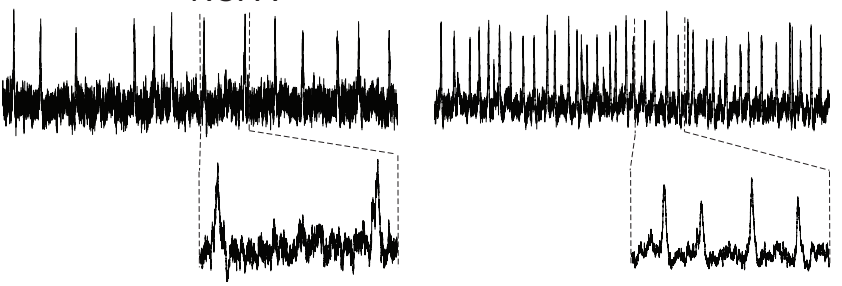

DPCPX

DPCPX
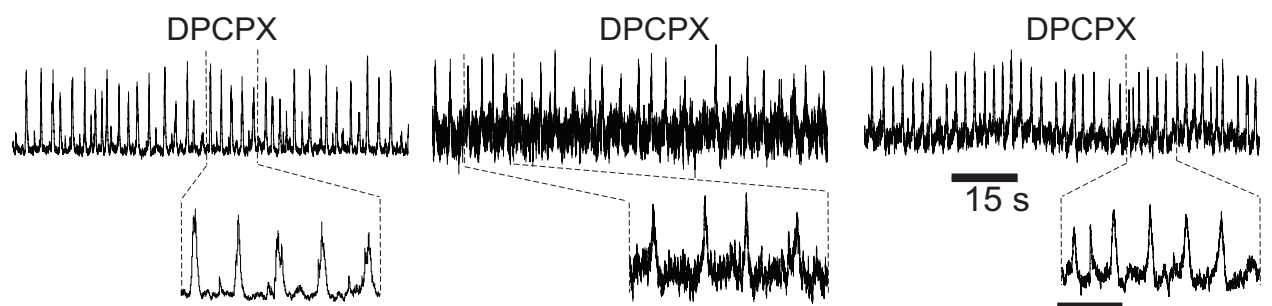

$15 \mathrm{~s}$

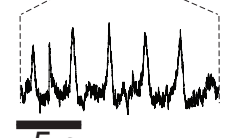

B. i.

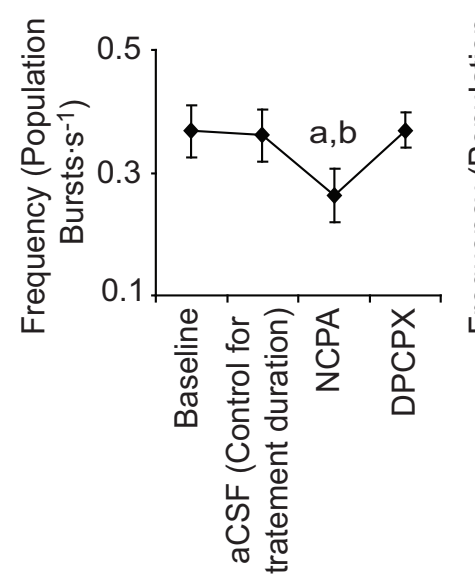

ii.

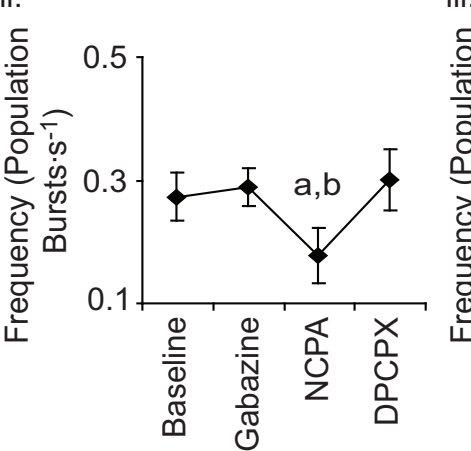

iii.

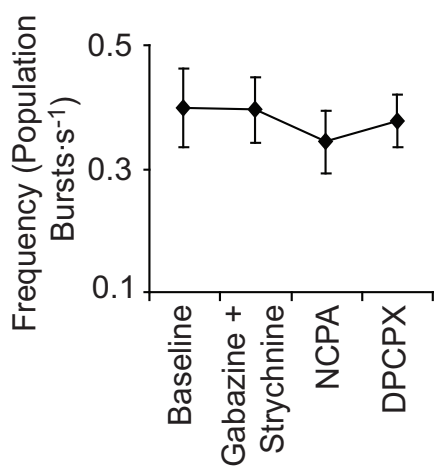

Figure 4

Effects of $A_{1} R$ activation on preBötC rhythmogenesis in island preparations. A. Representative effects of NCPA (I $\mu \mathrm{M})$ alone, with gabazine $(20 \mu \mathrm{M})$ and in combination with $20 \mu \mathrm{M}$ gabazine and I $\mu \mathrm{M}$ strychnine. B. As with slice preparations, NCPA alone (i) or in combination with gabazine (ii) decreased burst frequency. By contrast to slices, NCPA applied in combination with gabazine and strychnine (iii) failed to affect burst frequency (a, value different from baseline at $P<0.05$, Tukey post-hoc test; $\mathbf{b}$, value different from the second step of treatment - either continued aCSF, application of gabazine, or application of gabazine and strychnine - at $P<0.05$, Tukey post-hoc test). 
A.

$$
\mathrm{V}_{\text {hold }}=-60 \mathrm{mV}
$$
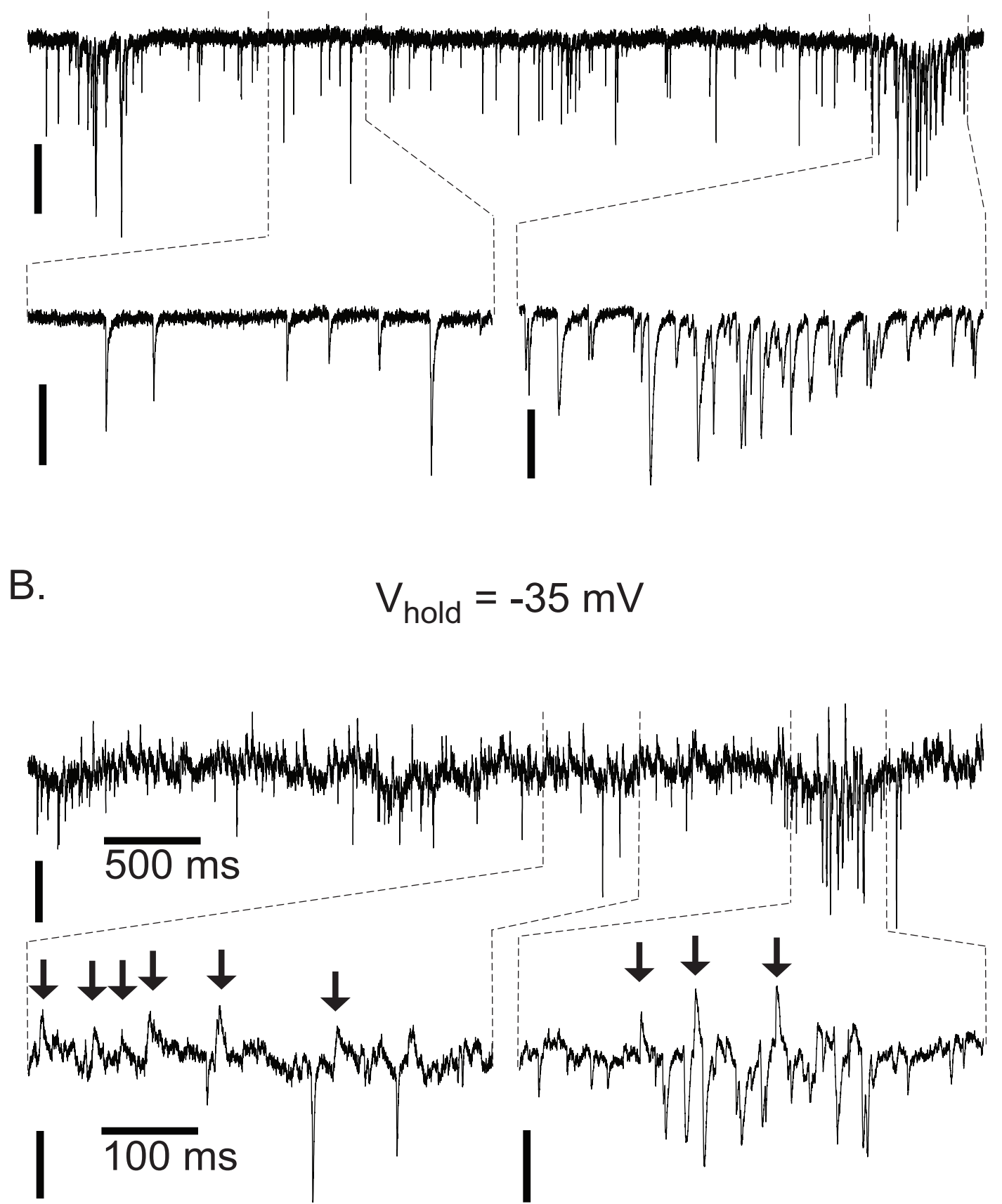

Figure 5

Synaptic inputs to preBötC neurons. A. Spontaneous postsynaptic currents from an inspiratory neuron voltage clamped at $-60 \mathrm{mV}$. Note both iPSCs from ePSCs appear as inward currents. B. The same neuron as in A, but voltage clamped at -35 $\mathrm{mV}$. Note that chloride-mediated synaptic currents now appear as outward currents (arrows). Although it is impossible to accurately measure the amplitude or frequency of excitatory or inhibitory inputs during inspiration-related bursts of synaptic input it is possible to distinguish between excitatory and inhibitory inputs during the interburst interval. Vertical scale: 50 pA. 
ing population bursts inhibitory and excitatory inputs occurred at a high enough frequency that the resultant summation/interference prohibited evaluation of synaptic inputs during this period. Rather, sEPSC and sIPSC frequencies were evaluated during the period between population bursts.

During baseline recording, inspiration-related neurons (those receiving increased excitatory input during the population burst) within slice preparations received sEPSCs at $15.6 \pm 3.6 \mathrm{~Hz}$, and sIPSCs at $17.5 \pm 5.3 \mathrm{~Hz}$ (Fig. 6B. Strychnine eliminated almost all sIPSCs, reducing their frequency to $0.6 \pm 0.1 \mathrm{~Hz}(\mathrm{n}=8 ; \mathrm{P}=0.001)$, without noticeably affecting sEPSC frequency (Fig. 6A, C). NCPA further decreased the frequency of sIPSCs to $0.3 \pm 0.1 \mathrm{~Hz}$ $(\mathrm{n}=8 ; \mathrm{P}=0.001)$. In each of the 8 neurons treated sequentially with strychnine and then NCPA, subsequent treatment with bicuculline eliminated all remaining sIPSCs. As with sIPSCs, NCPA decreased the frequency of sEPSCs received by inspiratory neurons, in this case from $15.6 \pm 3.6$ to $4.0 \pm 1.4 \mathrm{~Hz}(\mathrm{n}=8, \mathrm{P}=0.004$; Fig. $6 \mathrm{C})$.

Reducing slice preparations to islands reduced the combined frequency of sIPSCs and sEPSCs received by inspiration-related neurons by 59\%, $(n=13$ of each type of preparation; $\mathrm{P}=0.004$, Mann-Whitney Rank Sum Test; Fig. 6A, B). Reducing medullary slices to island preparations decreased sEPSC frequency in inspiration-related neurons from $19.8 \pm 3.8$ ( $\mathrm{n}=13$ slices) to $8.1 \pm 2.4 \mathrm{~Hz}$ ( $\mathrm{n}$ $=13$ islands; $\mathrm{P}<0.001$, Mann-Whitney Rank Sum Test $)$. Conversion from medullary slice to island preparation also appeared to reduce sIPSC frequency in inspirationrelated neurons (from $17.5 \pm 5.3 \mathrm{~Hz}$ to $7.6 \pm 2.8 \mathrm{~Hz}$ ). However, this change failed to attain statistical significance $(\mathrm{n}=13$ of each type or preparation, $\mathrm{P}=0.167$; Fig. $6 B)$.

Although island preparations received synaptic inputs at lower frequencies than slice preparations, their response to NCPA, in this regard, was much the same. Within island preparations, strychnine reduced sIPSC frequency from $7.6 \pm 2.8$ to $0.5 \pm 0.1 \mathrm{~Hz}(\mathrm{n}=6, \mathrm{P}<0.001$; Fig. $6 \mathrm{C})$. Addition of NCPA further decreased $\mathrm{GABA}_{\mathrm{A}}$ ergic sIPSC frequency to $0.2 \pm 0.1 \mathrm{~Hz}$ (Mann-Whitney Rank Sum Test, $\mathrm{P}=0.041)$, and decreased sEPSC frequency to $2.0 \pm 1.2 \mathrm{~Hz}$ $(\mathrm{n}=6$, Two Sample t-test, $\mathrm{P}=0.035)$.

\section{Effects of $A_{l} R$ activation on membrane properties}

Since $A_{1} R$ activation is known to affect membrane properties, and in some neurons overall excitability, we examined the effects of NCPA on the $\mathrm{R}_{\mathrm{in}} \mathrm{I}_{\mathrm{Na}}$ (only without synaptic isolation) and $\mathrm{I}_{\mathrm{Kd}}$ of inspiratory preBötC neurons. In slice and island preparations $(n=10)$ bathed in normal aCSF, NCPA decreased $R_{\text {in }}$ from $389.2 \pm 130.0$ to $287.7 \pm 113.3 \mathrm{M} \Omega$ (Paired t-test, $\mathrm{P}<0.05$ ). After $15 \mathrm{~min}$ of recording, the $\mathrm{R}_{\mathrm{in}}$ of one of these neurons increased by $8 \%$ and in two others $\mathrm{R}_{\text {in }}$ remained essentially unchanged from baseline ( $<5 \%$ change). Overall, steady state outward currents evoked by voltage steps applied in $10 \mathrm{mV}$ increments between $-80 \mathrm{mV}$ and $+20 \mathrm{mV}$ were unaffected by NCPA (Paired t-test, $P>0.1$ ). Similarly, in the presence of NCPA voltage steps from $-60 \mathrm{mV}$ to $-40 \mathrm{mV}$ evoked $\mathrm{I}_{\mathrm{Na}}$ $(-4192.2 \pm 919.8 \mathrm{pA})$ similar to that evoked by identical voltage steps under baseline conditions $(-5291.2 \pm 1387.9$ $\mathrm{pA} ; \mathrm{n}=5, \mathrm{P}=0.53$ ).

To verify that NCPA directly affected $\mathrm{A}_{1} \mathrm{R}$ activation in the cells examined, rather than affecting release of other substances onto the patched cells, we repeated the preceding set of experiments (minus the measurement of $\mathrm{I}_{\mathrm{Na}}$ ) in the presence of TTX, $\mathrm{Cd}^{++}$, elevated $\mathrm{Mg}^{++}$and minimal extracellular $\mathrm{Ca}^{++}$(as close to no $\mathrm{Ca}^{++}$as possible). Whereas input resistance remained nearly constant in the modified aCSF (15 min control for NCPA treatment period; Fig. 7Ai, addition of NCPA decreased $R_{\text {in }}$ from $306.9 \pm 38.4$ to $200.8 \pm 34.0 \mathrm{M} \Omega(\mathrm{n}=7$, Paired t-test, $\mathrm{P}=0.018)$. By contrast to its effects on $\mathrm{R}_{\mathrm{in}}$, NCPA produced no detectable effect on (leak-corrected) $\mathrm{I}_{\mathrm{Kd}}(\mathrm{n}=5$; Fig. 7B, C).

\section{Discussion}

In preparations representing levels of biological organization from tissue through whole-organism, $\mathrm{A}_{1} \mathrm{R}$ activation depresses neuronal-network activity underlying respiratory rhythmogenesis $[23,24]$. Although $\mathrm{GABA}_{\mathrm{A}}$ ergic and glycinergic transmission affect the patterning and excitability of the respiratory network within in vitro preparations from neonatal mammals, the data presented herein show that the depression of preBötC rhythmogenesis by $A_{1} R$ activation is unaffected by reducing the overall level of synaptic input received by preBötC neurons, or by antagonizing $\mathrm{GABA}_{\mathrm{A}}$ or $\mathrm{GABA}_{\mathrm{A}}$ and glycine receptors. Thus, while the postsynaptic currents/potentials caused by $\mathrm{GABA}_{\mathrm{A}} /$ glycine receptor activation may integrate with the modulatory effects of $A_{1} R$ activation, the relative contribution of such integration to the combined effect is minor. The intracellular data presented herein are consistent with the notion that $A_{1} R$-mediated depression of network activity may involve modulation of resting membrane properties as well as suppression of synaptic release.

The preBötC receives synaptic input from other regions within the slice preparation. Modulation of at least some of these inputs, such as the contralateral preBötC, can affect the pattern of preBötC output $[10,34]$. Converting the slice to an island preparation removes the somata of many neurons sending axons to the preBötC. In excised preparations representing a variety of CNS regions, axon terminals severed from their somata continue to release messenger for a period of time after being cut away. In 
A.

Slice Baseline

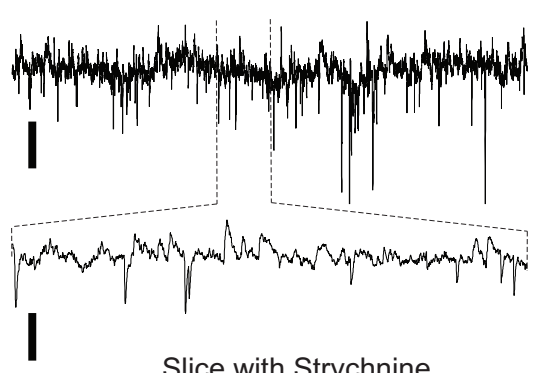

Slice with Strychnine

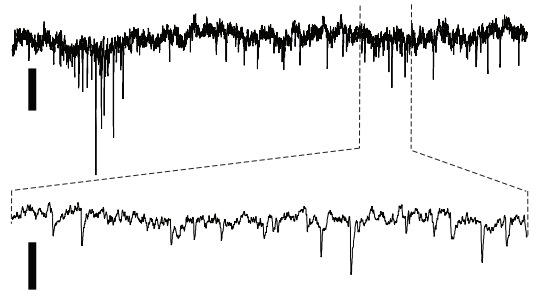

Slice with Strychnine and NCPA

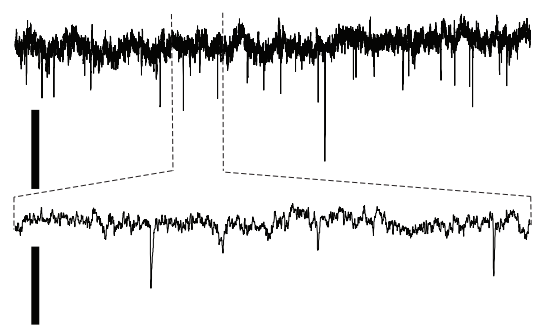

Island Baseline

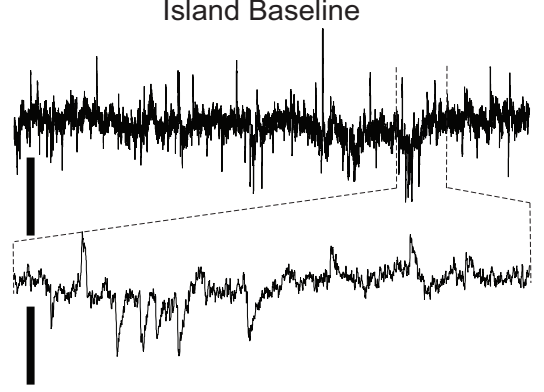

Island with Strychnine

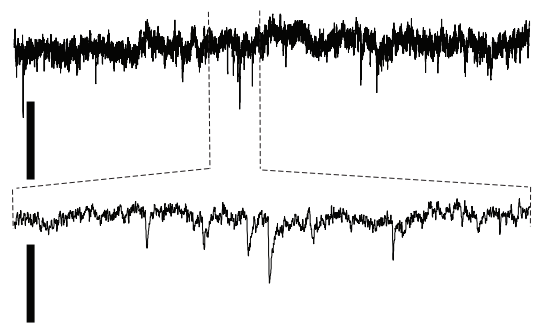

Island with Strychnine and NCPA

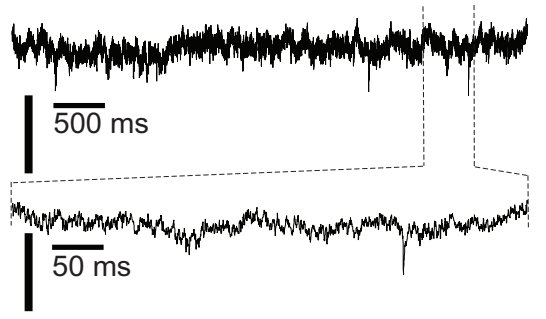

B.

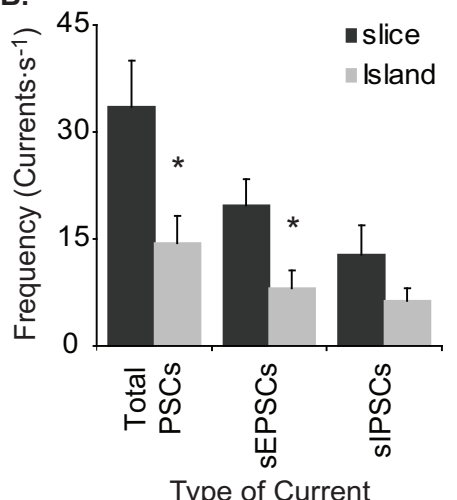

c.

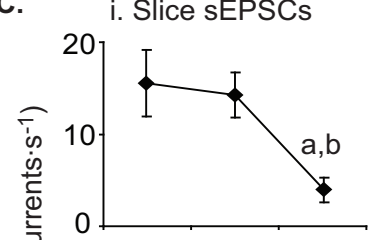

ii. Slice sIPSCs

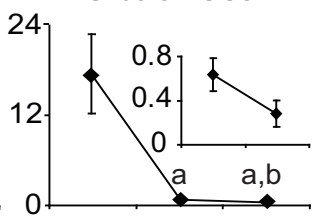

iv. Island SIPSCs
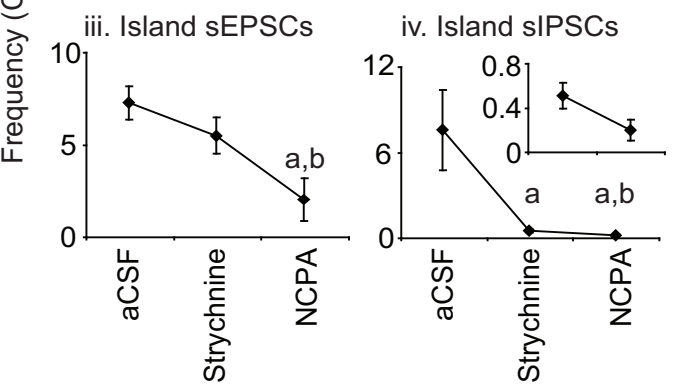

\section{Figure 6}

Manipulation of $A_{1} \mathbf{R}$ affects synaptic input to preBötC neurons. A. Representative current traces from slice (left) and island preparations (right). Vertical scale: 50 pA. B. Converting slices to island preparations reduced the frequency of total sPSCs and sEPSCs evoked in preBötC neurons ( ${ }^{* P}<0.05$, Two-sample t-test). This trend appeared to hold true for sIPSCs but did not attain statistical significance. C. NCPA $(\mathrm{I} \mu \mathrm{M})$ decreased the frequency of sEPSCs and sIPSCs received by preBötC neurons within slice (i, ii) and island preparations (iii, iv) in the presence of strychnine $(\mathrm{I} \mu \mathrm{M})$. The insets in (ii) and (iv) are magnified views of sIPSC frequencies in the presence of strychnine. Letters above columns show difference from mean frequency under baseline $(\mathbf{a}, \mathrm{P}<0.05)$ conditions and in the presence of strychnine $(\mathbf{b}, \mathrm{P}<0.05)$. 


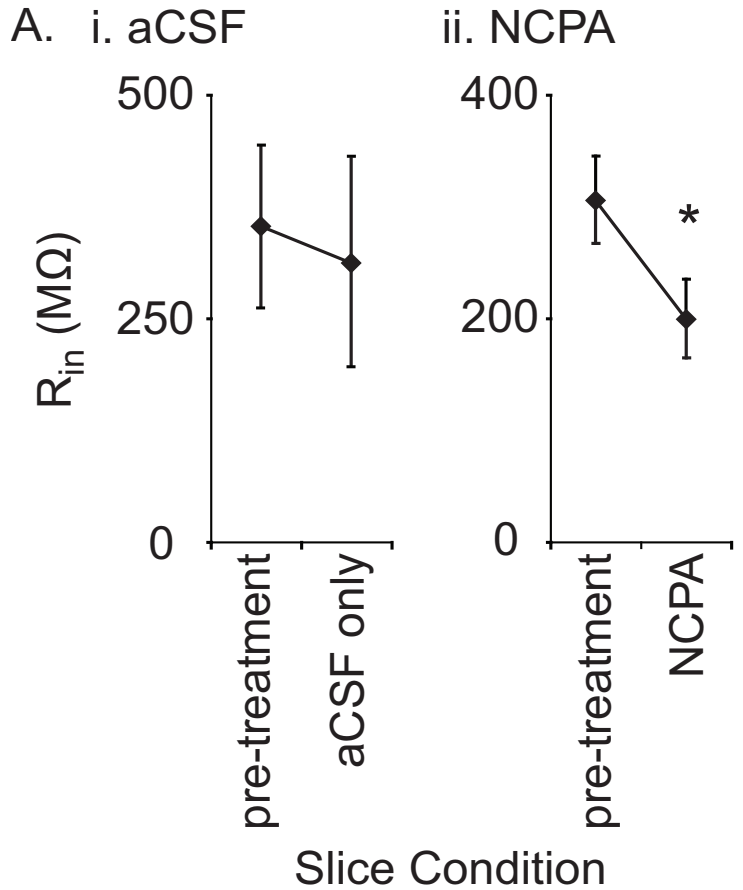

B.

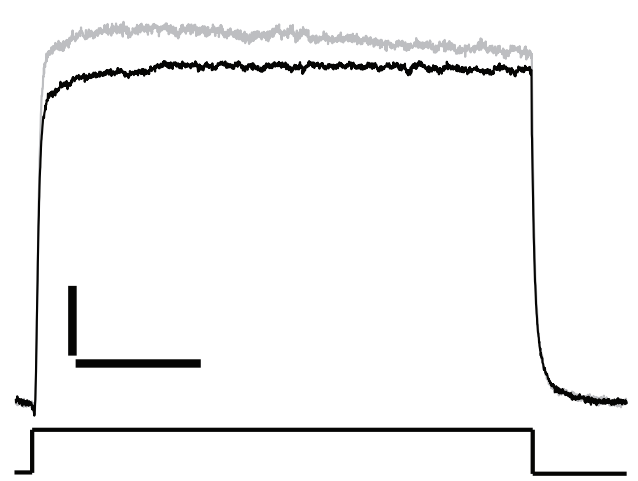

C.

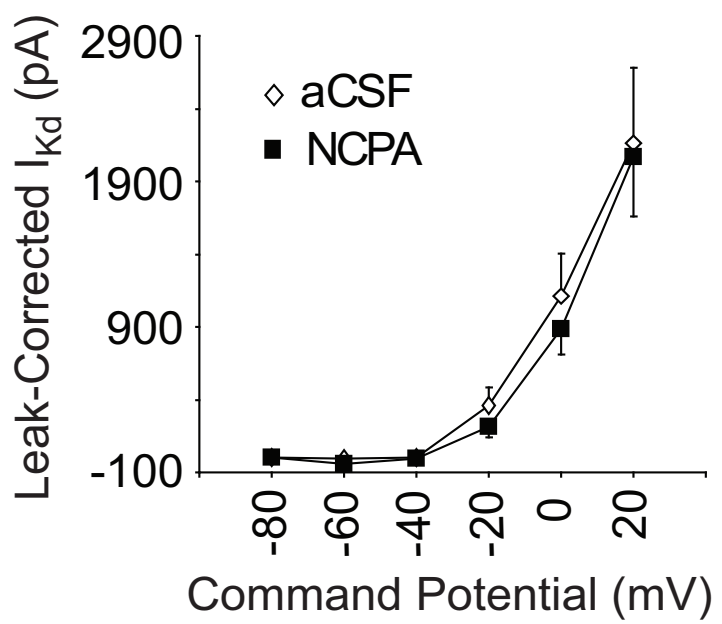

Figure 7

\section{Figure 7}

Effects of $A_{1} R$ activation on individual inspirationrelated preBötC neurons. A. NCPA $(I \mu M)$ decreased $R_{\text {in }}$ of synaptically isolated neurons $(n=7 ; * P<0.05)$. $B$. In this representative pair of whole cell current traces evoked by a voltage step from -60 to $20 \mathrm{mV} \mathrm{I}_{\mathrm{Kd}}$ is similar during recording in normal aCSF (black trace) and in NCPA (grey trace). Vertical scale: 100 pA; time scale: 50 ms. C. Mean current-voltage relationship for inspiratory neurons $(n=5$; error bars represent SEM).

fact, such release may be affected by the application of modulatory substances to the cut terminals [35]. However, converting the slice preparation to the island preparation reduces synaptic input to preBötC neurons (e.g., Fig. 6) suggesting that a large proportion of cut terminals in the island lose much, if not all, of their function shortly after being cut and/or that conversion leads to a decrease in intra-network communication. Activation of $A_{1} R$ depresses preBötC rhythmogenesis similarly in slice and island preparations, the latter representing a condition of reduced synaptic transmission. These findings, are consistent with the notion that the modulatory effects of $A_{1} R$ activation, although likely to integrate with concurrent synaptic inputs, are greater in their overall effect on preBötC activity than are $\mathrm{A}_{1} \mathrm{R}$-induced changes in the net synaptic input to preBötC neurons from sources originating outside the preBötC.

Although not required for rhythmogenesis in the neonatal respiratory network $\mathrm{GABA}_{\mathrm{A}}$ ergic and glycinergic transmission affect the pattern of respiratory network output [28$31,33,36]$ and blocking these forms of communication increases network excitability [31,32]. Here antagonizing $\mathrm{GABA}_{\mathrm{A}}$ and glycine receptors induced seizure-like bursting in slice preparations. Within the island preparation antagonism of $\mathrm{GABA}_{\mathrm{A}}$ and glycine receptors appeared to synchronize preBötC bursting, increasing burst amplitude [34]. Interestingly, this apparent synchronization during $\mathrm{GABA}_{\mathrm{A}}$ and glycine receptor antagonism occurred in islands from both very young (postnatal day 0- postnatal day 4), and older (postnatal day 4- postnatal day 7) mice. Although the $\mathrm{Cl}^{-}$equilibrium potential of preBötC neurons shifts from depolarizing to hyperpolarizing at around embryonic day 19 [33] for mice, this shift is not apparent until after postnatal day 2 [30] when medullary slice preparations are bathed in aCSF containing elevated $\mathrm{K}^{+}[30,33]$.

As noted above, $\mathrm{GABA}_{\mathrm{A}}$ ergic and glycinergic transmission affect respiratory network excitability and the pattern of respiratory network bursting. Accordingly, this study determined whether the blocking the postsynaptic cur- 
rents/potentials evoked by activation of $\mathrm{GABA}_{\mathrm{A}}$ and glycine receptors may alter the extent of network depression observed during $A_{1} R$ activation. That is, do the postsynaptic potentials evoked by $\mathrm{GABA}_{\mathrm{A}^{\prime}}$ or $\mathrm{GABA}_{\mathrm{A}}$ and glycine receptor activation integrate synergistically with the depressive modulatory effects of $A_{1} R$ activation? The lack of any noticeable difference in the response to $A_{1} R$ activation between slices in standard aCSF from those in aCSF with gabazine or with gabazine and strychnine suggests that the postsynaptic currents/potentials evoked by baseline $\mathrm{GABA}_{\mathrm{A}} /$ glycine receptor activation contribute little, if at all, to a potential combined effect.

In the medullary slice preparations used for this study baseline preparation-to-preparation variability in burst frequency was reasonable and similar between treatment groups. Had we evaluated the variability in burst-burst interval for slices (e.g., by calculating a regularity score), treatment with gabazine, or with combined gabazine and strychnine, which induced bursts of seizure-like activity, would likely have been shown to increase the variability in interburst interval (e.g., decrease burst regularity). By contrast to the frequency of bursting produced by slices, that produced by the island preparations used in this study tended to be somewhat more variable; whereas the slices from which islands were obtained burst at $0.2-0.5$ $\mathrm{Hz}$, the islands burst at $0.1-0.7 \mathrm{~Hz}$. To minimize baseline island variability and the number of animals consumed to obtain island preparations we limited the islands used to only those bursting between 0.2 and $0.6 \mathrm{~Hz}$. Given that the island preparation represents the most reduced preparation available for studying preBötC rhythmogenesis, it is perhaps not surprising that the frequency of bursting would be more variable in islands than in slices. In their initial description of the island preparation Johnson and colleagues [34] found that islands generated bursts at a higher frequency than slice preparations and that the SEM for preparation-to-preparation burst frequency was twice that in island preparations compared to slice preparations.

Although it did not do so in this study, using island preparations bursting over a wider range of baseline frequencies than slice preparations could contribute to a higher baseline frequency in islands than in slice preparations. However, such a difference would not, on its own, be likely to cause the differences in baseline burst frequency observed between island preparation treatment groups. Whereas islands used for testing the effects of NCPA in standard aCSF (Fig. 4A) burst at $0.37 \pm 0.04 \mathrm{~Hz}$, those used to examine the effects of NCPA in the presence of gabazine burst at $0.27 \pm 0.04 \mathrm{~Hz}$ and those used to evaluate the effects of NCPA in the presence of gabazine and strychnine burst at $0.40 \pm 0.06 \mathrm{~Hz}$. This variability resulted from the distribution of baseline burst frequen- cies produced by island preparations in the various treatment groups. Whereas the burst frequencies generated by islands in the first (testing NCPA in standard aCSF) of these three groups were distributed fairly evenly between 0.2 and $0.6 \mathrm{~Hz}$, those generated by islands in the second group (testing NCPA in the presence of gabazine) were distributed near the lower portion of the range with two of the islands bursting at the lower cutoff frequency. The frequency of bursts generated by island preparations in the third group (testing NCPA in the presence of gabazine and strychnine) clustered near the upper end of the allowed range with 2 of the preparations generating population-level bursts at the upper frequency limit. Although baseline firing frequency varied between island groups, the responses of those used to test the effects of NCPA and DPCPX in standard aCSF, or in aSCF containing gabazine were, as shown above, largely similar to those in the corresponding slice preparations. Both the increased baseline variability of islands and their responses to treatment may reflect the importance of modulatory input to preBötC neurons from other regions, such as the contralateral preBötC, and/or reduced intra-network communication.

Under normoxic baseline conditions it is unlikely that the preBötC would experience a substantial rise in extracellular adenosine concomitant with a substantial decrease in extracellular GABA and glycine concentration. However, hypoxic stress, after stimulating an initial augmentation of respiratory network activity, depresses respiratory network activity and decreases extracellular GABA levels [37] and glycinergic transmission [38] within the ventral respiratory group. These latter two effects are of interest since, as noted above, reducing $\mathrm{GABA}_{\mathrm{A}}$ ergic and glycinergic transmission within the neonatal respiratory network tend to increase network activity [29-31]. However, while hypoxia decreases GABA and glycine-mediated transmission, it also increases extracellular adenosine and serotonin levels, depresses extracellular glutamate levels [37] and alters a variety of membrane properties [39-43]. Although adenosine represents only one of numerous variables that contribute to hypoxic depression of respiratory network output, the data presented here verify that $A_{1} R$ activation is sufficient to overcome potential increases in network excitability caused by reduction in GABA and glycine transmission and in so doing depress preBötC bursting [c.f. $[22-24,44]]$.

Throughout most of this study excitatory synaptic transmission between preBötC neurons was left intact so that population-level effects could be observed. By affecting presynaptic mechanisms of synaptic transmission, such as axon-terminal $\mathrm{Ca}^{++}$conductances, $\mathrm{A}_{1} \mathrm{R}$ activation can directly affect synaptic transmission $[45,46]$. In fact, our data show that NCPA decreased synaptic inputs to preBötC neurons. Thus, the data presented herein do not rule 
out the possibility that $A_{1} R$ activation may depress preBötC rhythmogenesis by directly inhibiting excitatory transmission between preBötC neurons. In fact, imunohistochemical data suggest that $A_{1} R$ are found at the axon terminals of interneurons within a variety of CNS regions, including the NTS where they may be involved in regulating transmitter release [47]. However, $A_{1} R$ activation clearly decreases excitability of preBötC neurons, an effect that alone can decrease transmitter release.

During the present study $A_{1} R$ activation decreased the $R_{\text {in }}$ of preBötC neurons regardless of whether or not those neurons were synaptically isolated from the rest of the network. Although not a quantitative measure of neuronal excitability due to its reliance on access resistance and seal resistance, holding current can reflect changes in membrane voltage that would occur, were the neuron not being subjected to voltage clamp. During the present study holding current increased (became more positive) in $60 \%$ of the NCPA-treated neurons examined in synaptic isolation. By contrast, the holding current of control neurons (those examined in low $\mathrm{Ca}^{++} / \mathrm{High} \mathrm{Mg}^{++}$aCSF with TTX, but without NCPA) became more negative over time. In brainstem-spinal cord preparations Herlenius and Lagercrantz found that $A_{1} R$ activation decreased the $\mathrm{V}_{\mathrm{m}}$ of expiratory neurons but did not affect $\mathrm{R}_{\mathrm{in}}$ or $\mathrm{V}_{\mathrm{m}}$ of inspiratory neurons [23]. The difference between their study and the data presented herein may reflect the types of neurons from which data were obtained. Whereas Herlenius and Lagercrantz [23] defined inspiratory neurons in terms of discharge characteristics, here inspiratory neurons were defined as any that received a barrage of synaptic input during the population burst. Some neurons received concurrent barrages of EPSCs and IPSCs resulting in little or no net inward/outward current, suggesting that although defined as inspiratory per the criteria used herein, these may have actually been expiratory neurons.

Although NCPA affected resting membrane properties in this study, it did not affect whole-cell currents evoked by depolarizing voltage steps. However, depolarizing voltage steps activate multiple conductances in preBötC neurons, and different types of inspiration-related neuron express different combinations of voltage-sensitive ion channels [12]. In other neurons $\mathrm{A}_{1} \mathrm{R}$ activation affects $\mathrm{Ca}^{++}$conductance $[17,25,48]$. It is possible that one or more of types of these conductances were affected by $A_{1} R$, but in combination with whole cell $\mathrm{K}^{+}$conductances such changes were insufficient to affect total transmembrane current. Although beyond the scope of the present study, future work will provide a more detailed dissection of the effects of $A_{1} R$ activation on various membrane conductances. Rhythmogenesis within the preBötC of neonatal mice is thought to require synaptic interactions and the activity of pacemaker neurons $[3,5,9,10,12,32,34,49-53]$. Upcom- ing research in our laboratory will examine whether $A_{1} R$ activation decreases the excitability and rhythmic production of action potential bursts by synaptically-isolated preBötC pacemaker neurons.

\section{Conclusion}

In this study $A_{1} R$ activation depressed preBötC rhythmogenesis by acting directly on the preBötC within slice and island preparations, even though the frequency of synaptic currents in preBötC neurons is extensively reduced in the latter preparation. Moreover, $\mathrm{A}_{1} \mathrm{R}$-mediated depression of preBötC rhythmogenesis was similar in slices bathed in standard aCSF, in slices and islands bathed in aCSF containing gabazine, and in slices bathed in gabazine and strychnine. Even when chemical communication between preBötC neurons and other cells within the tissue was blocked, $A_{1} R$ activation affected resting membrane properties of preBötC neurons in a manner consistent with decreasing neuronal excitability. Agonizing $A_{1} R$ with NCPA decreased the frequency of synaptic inputs to preBötC neurons in both types of preparation. Together these data support the notion that, $\mathrm{A}_{1} \mathrm{R}$-medated depression of preBötC rhythmogenesis involves both decreased neuronal excitability and inhibition of chemical synaptic communication between preBötC neurons. Although postsynaptic currents and potentials resulting from $\mathrm{GABA}_{\mathrm{A}}$ and glycine receptor activation may integrate synergistically with the modulatory actions of $A_{1} R$ activation, the data herein suggest that their relative contribution to such depression is minor.

\section{Methods}

\section{Isolation and Maintenance of in vitro Preparations}

All procedures were carried out according to guidelines established by NIH and the National Research Counsel, and were approved by the Institutional Animal Care and Use Committee at Central Michigan University. Slices of mouse medulla oblongata were obtained from male and female Swiss-Webster mice ( $=7 \mathrm{~d}$ old) that were decapitated at the $\mathrm{C} 3 / \mathrm{C} 4$ vertebral level. The brainstem was isolated in ice-cold aCSF (in mM: $118 \mathrm{NaCl}, 3 \mathrm{KCl}, 1.5$ $\mathrm{CaCl}_{2}, 1 \mathrm{MgCl}_{2}, 25 \mathrm{NaHCO}_{3}, 1 \mathrm{NaH}_{2} \mathrm{PO}_{4}$, and 30 D-Glucose) saturated with carbogen gas $\left(95 \% \mathrm{O}_{2}\right.$ and $\left.5 \% \mathrm{CO}_{2}\right)$. The cerebrum and cerebellum were dissected away and the isolated brainstem was glued to an agar block using cyanoacrylate glue. This mount was secured in a vibrating microtome with the rostro-caudal axis of the brainstem and spinal cord tilted such that the top of the preparation was slightly farther away from the face of the microtome than the lower portion (the axis of the tissue was oriented $\sim 110^{\circ}$ from the plane in which the microtome blade advanced). Serial sections ( $c a .300 \mu \mathrm{M}$ thick) were removed from the rostral surface to reveal the $4^{\text {th }}$ ventricle. Then, $c a$. $200 \mu \mathrm{m}$-thick sections were removed until the region containing the preBötC was revealed, recognized 
by the presence of the obex at the caudal closure of the fourth ventricle, the appearance of XII nerve tracts and the IO. At this level, a $600 \mu \mathrm{m}$-thick slice was removed and immediately transferred to a recording chamber.

Slice viability was sustained by recirculating carbogen-saturated aCSF $\left(29.5^{\circ}-30.5^{\circ} \mathrm{C} ; \mathrm{pH} 7.4\right)$ between a reservoir and the recording chamber ( $200 \mathrm{ml}$ total volume). Thirty minutes before baseline recording, the potassium concentration of the aCSF was elevated from $3 \mathrm{mM}$ to $8 \mathrm{mM}$. Slices were subjected to each experimental condition for 20 to 30 minutes. Only slices that generated bursts at frequencies between 0.2 and $0.5 \mathrm{~Hz}$ were used in this study.

\section{Island preparations}

Transverse medullary slices were reduced to island preparations as described by Johnson et al. [34]. To summarize, following baseline recordings regions of the slice immediately surrounding the preBötC were cut away using microiridectomy scissors. Cuts were made from the ventral margin of the slice adjacent (lateral) to the IO along a curve following and slightly lateral to the XII nerve tract. Then from a point $\sim 1 / 3$ of the way between the ventral fissure and the dorsal cusp of the fourth ventricle the next cut progressed laterally to the medial margin of SP5. The final cut then progressed along the ventromedial margin of SP5 to the ventrolateral surface of the slice, thereby removing the contralateral preBötC, NTS, SP5, XIIn, XII tract, and the IO (c.f. Johnson et al. 2001). The frequency at which islands generated population bursts was somewhat more variable than that observed in slice preparations. Accordingly, only islands that generated bursts of integrated network activity at frequencies between 0.2 and $0.6 \mathrm{~Hz}$ were used in this study.

\section{Extracellular recordings}

Extracellular electrodes were fabricated from borosilicate glass pipettes, filled with aCSF, and connected to a homemade AC-coupled pre-amplifier (100 times amplification). Raw traces were filtered between $(0.3-3 \mathrm{kHz})$ and amplified an additional 100 times (Amplifier model P15, Grass Technologies, West Warwick, RI, USA) before being sent to a hardware integrator (50 ms time constant) and an analog-digital converter (ITC-18, Instrutech Corp., Port Washington, NY, USA). Both raw and integrated traces were recorded on the hard disk of a personal computer using Chart 4.0 (ADInstruments, Inc., Colorado Springs, CO, USA) or PatchMaster v2.11 (HEKA Instruments, Inc., Southboro, MA, USA).

\section{Whole-cell patch clamp recordings}

Whole-cell patch clamp recordings were obtained using unpolished electrodes fabricated from thick-walled borosilicate glass (Warner Instruments, \# GC 150-10) and filled with (in mM) 140 K-Gluconate, $1 \mathrm{CaCl}_{2}, 2 \mathrm{MgCl}_{2}, 4$
$\mathrm{Na}_{2} \mathrm{ATP}, 10$ EGTA, and 10 HEPES (pH 7.2). Using nearinfrared Normarski optics (with a $40 \times$ objective) the tip of the patch electrode was positioned on the soma of a neuron within the preBötC. After a gigaohm seal was established, whole-cell configuration was established by applying repetitive pulses of negative pressure until the cell membrane within the electrode tip ruptured. Transmembrane currents were recorded using an EPC8 amplifier (HEKA Instruments, Inc.) and recorded on the hard disk of a personal computer via Patchmaster software and an ITC-18 data acquisition board. Currents were filtered at $2 \mathrm{KHz}$ using the internal Bessel filter of the amplifier and digitized at $10 \mathrm{kHz}$. Before recording any data from a cell, transient currents due to electrode and cell resistance and capacitance were minimized and serial resistance was $80 \%$ compensated. Recordings were corrected offline for a $15 \mathrm{mV}$ junction potential. With the solutions used herein, $\mathrm{Cl}^{-}$based spontaneous inhibitory postsynaptic currents (sIPSCs) appeared as outward cation currents (i.e., as an influx of $\mathrm{Cl}^{-}$) in cells voltage clamped at $-35 \mathrm{mV}$, while those triggered by excitatory neurotransmitters appeared as inward currents (sEPSCs). To track the quality of the recording, we monitored fundamental properties including input resistance $\left(R_{\text {in }}\right)$, access resistance $\left(R_{a}\right)$, holding current at $-60 \mathrm{mV}\left(\mathrm{I}_{\text {hold }}\right)$ and cell capacitance throughout baseline and experimental conditions. Recordings in which $R_{a}$ became greater than $10 \%$ of $R_{\text {in }}$ were discarded as were any in which holding current at $-60 \mathrm{mV}$ exceeded (became more negative than) $-400 \mathrm{pA}$. Whereas $\mathrm{R}_{\mathrm{a}}$ and cell capacitance were monitored using the manual adjustments on the amplifier, I hold was recorded directly from traces and $R_{\text {in }}$ was calculated based on the current observed (without leak subtraction) during a $20 \mathrm{~ms}$-long voltage step from a holding potential of $-60 \mathrm{mV}$ to a command potential of $-80 \mathrm{mV}$. Voltage-gated sodium currents $\left(\mathrm{I}_{\mathrm{Na}}\right)$ and steady state voltage gated potassium currents $\left(\mathrm{I}_{\mathrm{Kd}}\right)$ were evaluated using a voltage step protocol. From a holding potential of $-60 \mathrm{mV}$ we applied $200 \mathrm{~ms}$ long voltage steps from -80 to $20 \mathrm{mV}$ in $10 \mathrm{mV}$ steps. Linear leak currents were eliminated with an online $\mathrm{P} / 4$ leak subtraction protocol.

In a subset of voltage clamp experiments, the effects of NCPA on $R_{\text {in }}$ and $I_{K d}$ were evaluated using synapticallyisolated inspiratory neurons. Isolation was accomplished by bathing slices in aCSF lacking (severely reduced) $\mathrm{Ca}^{++}$, and containing Tetrodotoxin (TTX; $1 \mu \mathrm{M}), \mathrm{CdCl}_{2}(200$ $\mu \mathrm{M})$, and $\mathrm{MgCl}_{2}(10 \mathrm{mM})$.

\section{Solutions}

All drugs/toxins were applied by diluting stock solutions 1000 times in the recirculating bath reservoir. The concentrations listed represent the final working concentration for each agent. The adenosine $\mathrm{A}_{1}$-receptor agonist $\mathrm{N}^{6}{ }_{-}$ Cyclopentyl Adenosine (NCPA; $1 \mu \mathrm{M}$ ), the adenosine $A_{1^{-}}$- 
receptor antagonist 1,3-Dipropyl-8-cyclopentylxanthine (DPCPX; $1 \mu \mathrm{M}$ ), the $\mathrm{GABA}_{\mathrm{A}}$-receptor antagonists bicuculline $(20 \mu \mathrm{M}$, free base) and gabazine $(20 \mu \mathrm{M})$ were prepared as stock solutions in DMSO. The glycine receptor antagonist strychnine $(1 \mu \mathrm{M})$ and TTX were prepared as stock solutions in deionized water.

\section{Data analysis}

Throughout this report, the term baseline is used in reference to measurements performed prior to addition of drugs. The term control is used to refer to recording in aCSF without drug after a period intended to match that of drug application in a separate preparation. Extracellular data (burst frequency and amplitude) were measured using population bursts occurring during the final 2-minutes of each treatment (Igor Pro 4.07, Wavemetrics Inc., Oswego, OR). All data were tested for normality (Minitab v. 14, Minitab, Inc., State College, PA, USA). Extracellular data having a normal distribution were analyzed using repeated measures ANOVA followed by Tukey post-hoc comparisons to determine differences between specific treatments, when appropriate. Non-normal extracellular data were evaluated using Friedman's Repeated Measures ANOVA on ranks. Again differences between specific treatments were evaluated with Tukey post-hoc tests. Normally distributed intracellular data were compared using paired-t tests for comparisons within a cell, or two-sample t-tests when comparing cells from separate treatments. Non-normal intracellular data were compared using the Mann-Whitney Rank Sum test. Differences were considered significant at $\mathrm{P} \leq 0.05$. Data are presented as means \pm SE.

\section{Authors' contributions}

RJV performed most of the extracellular recordings from slice and island preparations, acquired some of the voltage clamp recording, and helped draft the manuscript. EJS conducted some extracellular recordings from slice preparations, most of the voltage clamp recordings, and provided critical feedback during manuscript preparation. JDK conceived of the study, designed the experiments, performed some of the extracellular recordings from slice preparations, carried out the statistical analyses, and was the primary writer of the manuscript. All authors read and approved the final manuscript.

\section{Acknowledgements}

The authors thank Drs. Justin Oh-Lee, Michael Sandstrom, and Jennifer Schisa for comments on early drafts of this manuscript. This research was supported by a Research Excellence Fund Award to JDK from the State of Michigan.

\section{References}

I. McCrimmon DR, Ramirez JM, Alford S, Zuperku EJ: Unraveling the mechanisms for respiratory rhythm generation. BioEssays 2000, 22(I):6-9.
2. Smith J, Ellenberger H, Ballanyi K, Richter D, Feldman J: Pre-Bötzinger complex: a brainstem region that may generate respiratory rhythm in mammals. Science 1991, 254:726-729.

3. Thoby-Brisson M, Ramirez JM: Identification of two types of inspiratory pacemaker neurons in the isolated respiratory neural network of mice. J Neurophysiol 200 I, 86(I): I04-I I 2.

4. Rekling JC, Feldman JL: Pre-Bötzinger complex and pacemaker neurons: hypothesized site and kernel for respiratory rhythm generation. Annu Rev Physiol 1998, 60(I):385-405.

5. Koshiya N, Smith JC: Neuronal pacemaker for breathing visualized in vitro. Nature 1999, 400(6742):360-363.

6. Lieske SP, Thoby-Brisson M, Telgkamp P, Ramirez JM: Reconfiguration of the neural network controlling multiple breathing patterns: eupnea, sighs and gasps [see comment]. Nat Neurosci 2000, 3(6):600-607.

7. Ramirez JM, Telgkamp P, Elsen FP, Quellmalz UJ, Richter DW: Respiratory rhythm generation in mammals: Synaptic and membrane properties. Respir Physiol 1997, I I 0(2-3):7I-85.

8. Richter DW, Spyer KM: Studying rhythmogenesis of breathing: comparison of in vivo and in vitro models. Trends Neurosci 200I, 24(8):464-472.

9. Ramirez J-M, Zuperku EJ, Alheid GF, Lieske SP, Ptak K, McCrimmon DR: Respiratory rhythm generation: converging concepts from in vitro and in vivo approaches? Respir Physiol Neurobiol 2002, I 4 I:43-56.

10. Butera R, Rinzel J, Smith JC: Models of respiratory rhythm generation in the pre-Bötzinger complex. I. Bursting pacemaker neurons. J Neurophysiol 1999, 8 I (I):382-397.

II. Thoby-Brisson M, Telgkamp P, Ramirez JM: The role of the hyperpolarization-activated current in modulating rhythmic activity in the isolated respiratory network of mice. J Neurosci 2000 , 20(8):2994-3005

12. Pena F, Parkis MA, Tryba AK, Ramirez JM: Differential contribution of pacemaker properties to the generation of respiratory rhythms during normoxia and hypoxia. Neuron 2004, 43(I): $105-117$.

13. Funk GD, Smith JC, Feldman JL: Generation and transmission of respiratory oscillations in medullary slices: role of excitatory amino acids. J Neurophysiol 1993, 70(4): |497-I5I5.

14. Fowler J: Modulation of neuronal excitability by endogenous adenosine in the absence of synaptic transmission. Brain Res 1988, 463:368-373.

15. Gervitz LM, Lutherer LO, Davies DG, Pirch JH, Fowler JC: Adenosine induces initial hypoxic-ischemic depression of synaptic transmission in the rat hippocampus in vivo. Am J Physiol Regul Integr Comp Physiol 200 I, 280(3):R639-R645.

16. Bellingham M, Berger AJ: Adenosine suppresses excitatoryglutamatergic inputs to rat hypoglossal motornuerons in vitro. Neurosci Lett 1994, 177:143-146.

17. Mynlieff $M$, Beam $K$ : Adenosine acting at an $A_{1}$ receptor decreases $\mathbf{N}$-type calcium current in mouse motoneurons. J Neurosci 1994, I4(6):3628-3634.

18. Koos BJ, Maeda T, Jan C: Adenosine $A_{1}$ and $A_{2 A}$ receptors modulate sleep state and breathing in fetal sheep. J Appl Physiol 200I, 9 I(I):343-350.

19. Lagercrantz H, Yamamoto D, Fredholm BB, Prabhakar NR, von Euler $C$ : Adenosine analogues depress ventilation in rabbit neonates. Theophylline stimulation of respiration via adenosine receptors? Pediatr Res 1984, I 8(4):387-390.

20. Eldridge F, Millhorn D, Kiley J: Antagonism by theophylline of respiratory inhibition induced by adenosine. J Appl Physiol I985, 59(5): | 428-|433.

21. Brockhaus J, Ballanyi K: Anticonvulsant $\mathbf{A}_{\text {, }}$ receptor-mediated adenosine action on neural networks in the brainstem-spinal cord of newborn rats. Neuroscience 2000, 96(2):359-37I.

22. Herlenius E, Lagerspetz K, Yamamoto Y: Adenosine modulates inspiratory neurons and the respiratory pattern in the brainstem of neonatal rats. Pediatr Res 1997, 42:46-53.

23. Herlenius E, Lagercrantz $\mathrm{H}$ : Adenosinergic modulation ofrespiratory neurones in the neonatal rat brainstem in vitro. J Physiol (Lond) 1999, 5 I 8(Pt I): I59-I72.

24. Mironov SL, Langohr K, Richter DW: A, Adenosine Receptors Modulate Respiratory Activity of the Neonatal Mouse Via the cAMP-Mediated Signaling Pathway. J Neurophysiol 1999, 8 I (I):247-255. 
25. Umemiya M, Berger AJ: Activation of adenosine Al and A2 receptors differentially modulates calcium channels and glycinergic synaptic transmission in rat brainstem. Neuron 1994 13:1439-1446.

26. Pierrefiche O, Schwarzacher SW, Bischoff AM, Richter DW: Blockade of synaptic inhibition within the pre-Bötzinger complex in the cat suppresses respiratory rhythm generation in vivo. J Physiol (Lond) 1998, 509(I):245-254.

27. Monnier A, Alheid GF, McCrimmon DR: Defining ventral medullary respiratory compartments with a glutamate receptor agonist in the rat. J Physiol 2003, 548(3):859-874.

28. St John WM, Rybak IA, Paton JFR: Potential switch from eupnea to fictive gasping after blockade of glycine transmission and potassium channels. Am J Physiol Regul Integr Comp Physiol 2002, 283:R72I-R73I.

29. Bou-Flores C, Berger AJ: Gap junctions and inhibitory synapses modulate inspiratory motoneuron synchronization. J Neurophysiol 200I, 85: 1543-I55I.

30. Ritter $B$, Xhang W: Early postnatal maturation of $\mathbf{G A B A}_{\mathbf{A}^{-}}$ mediated inhibition in the brainstem respiratory rhythmgenerating network of the mouse. Eur J Neurosci 2000, 1 2:2975-2984.

31. Sebe JY, van Brederode JF, Berger AJ: Inhibitory Synaptic Transmission Governs Inspiratory Motoneuron Synchronization. Neurophysiol 2006, 96(I):39I-403.

32. Tryba AK, Pena F, Ramirez JM: Stabilization of Bursting in Respiratory Pacemaker Neurons. J Neurosci 2003, 23(8):3538-3546.

33. Ren J, Greer J]: Modulation of Respiratory Rhythmogenesis by Chloride-Mediated Conductances during the Perinatal Period. J Neurosci 2006, 26(1 4):372 I-3730.

34. Johnson SM, Koshiya N, Smith JC: Isolation of the kernel for respiratory rhythm generation in a novel preparation: The preBötzinger complex "island". J Neurophysiol 200I 85(4): 1772-1776.

35. Matsumoto N, Komiyama S, Akaike N: Pre- and postsynaptic ATP-sensitive potassium channels during metabolic inhibition of rat hippocampal CAI neurons. J Physiol (Lond) 2002, $54 I(2): 5 I I-520$

36. Shao XM, Feldman JL: Respiratory Rhythm Generation and Synaptic Inhibition of Expiratory Neurons in Pre-Botzinger Complex: Differential Roles of Glycinergic and GABAergic Neural Transmission. J Neurophysiol 1997, 77: I853-1860.

37. Richter DW, Schmidt-Garcon P, Pierrefiche O, Bischoff AM, Lalley PM: Neurotransmitters and neuromodulators controlling the hypoxic respiratory response in anaesthetized cats. Physiol 1999, 5 I 4(Pt 2):567-578.

38. St-John WM, Leiter JC: Gasping is elicited by briefer hypoxia or ischemia following blockade of glycinergic transmission. Respir Physiol Neurobiol 2002, I33(I-2): I67-I7I.

39. Mironov SL, Langohr K, Haller M, Richter DW: Hypoxia activates ATP-dependant potassium channels in inspiratory neurones of neonatal mice. J Physiol (Lond) 1998, 509.3:755-766.

40. Mironov SL, Langohr K, Richter DW: Hyperpolarization-activated current, Ih, in inspiratory brainstem neurons and its inhibition by hypoxia. Eur J Neurosci 2000, 12:520-526.

41. Mironov SL, Richter DW: Hypoxic modulation of L-type Ca(2+) channels in inspiratory brainstem neurones: intracellular signalling pathways and metabotropic glutamate receptors. Brain Res 2000, 869(I-2): I66-177.

42. Mironov SL, Richter DW: L-type Ca2+ channels in inspiratory neurones of mice and their modulation by hypoxia. J Physiol 1998, 5 I 2(Pt I):75-87.

43. Mironov SL, Richter DW: Cytoskeleton mediates inhibition of the fast $\mathrm{Na}+$ current in respiratory brainstem neurons during hypoxia. Eur J Neurosci 1999, I I:1831-1834.

44. Schmidt C, Bellingham M, Richter D: Adenosinergic modulation of respiratory neurones and hypoxic responses in the anaesthetized cat. J Physiol (Lond) 1995, 483:769-78I.

45. Chen G, van den Pol AN: Adenosine modulation of calcium currents and presynaptic inhibition of GABA release in suprachiasmatic and arcuate nucleus neurons. J Neurophysiol 1997, 77:3035-3047.

46. Dittman J, Regehr W: Contributions of calcium-dependent and calcium-independent mechanisms to presynaptic inhibition at a cerebellar synapse. J Neurosci 1996, 16(5):1623-1633.
47. Pickel V, Chan J, Linden J, Rosin D: Subcellular Distributions of Adenosine AI and A2A Receptors in the Rat Dorsomedial Nucleus of the Solitary Tract at the Level of the Aea Postrema. Synapse 2006, 60(7):496-509.

48. MacDonald RL, Skeritt JH, Werz MA: Adenosine agonists reduce voltage-dependent calcium conductance of mouse sensory neurones in cell culture. J Physiol (Lond) 1986, 370:75-90.

49. Guyenet PG: Novel two-rhythm generator theory of breathing in mammals. J Physiol (Lond) 2005, 570(2):407-420.

50. Del Negro CA, Koshiya N, Butera RJ Jr, Smith JC: Persistent Sodium Current, Membrane Properties and Bursting Behavior of Pre-Botzinger Complex Inspiratory Neurons In Vitro. J Neurophysiol 2002, 88(5):2242-2250.

51. Thoby-Brisson M, Ramirez JM: Role of inspiratory pacemaker neurons in mediating the hypoxic response of the respiratory network in vitro. J Neurosci 2000, 20(15):5858-5866.

52. Smith JC, Butera RJ, Koshiya N, Del Negro C, Wilson CG, Johnson SM: Respiratory rhythm generation in neonatal and adult mammals: the hybrid pacemaker-network model. Respir Physiol 2000, I 22(2-3): |3|-| 47 .

53. Kiehn O, Kjaerulff O, Tresch MC, Harris-Warrick RM: Contributions of intrinsic motor neuron properties to the production of rhythmic motor output in the mammalian spinal cord. Brain Res Bull 2000, 53(5):649-659.
Publish with BioMed Central and every scientist can read your work free of charge

"BioMed Central will be the most significant development for disseminating the results of biomedical research in our lifetime. "

Sir Paul Nurse, Cancer Research UK

Your research papers will be:

- available free of charge to the entire biomedical community

- peer reviewed and published immediately upon acceptance

- cited in PubMed and archived on PubMed Central

- yours - you keep the copyright
BioMedcentral 